\title{
Poly(butylene terephthalate)/polylactic acid based copolyesters and blends: miscibility-structure-property relationship
}

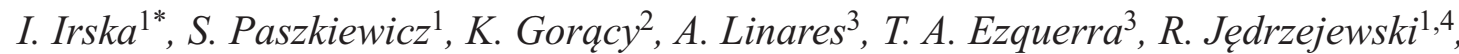 \\ Z. Rostaniec ${ }^{1}$, E. Piesowicz ${ }^{1}$ \\ ${ }^{1}$ Institute of Materials Science and Engineering, West Pomeranian University of Technology, Al. Piastów 19, \\ 70-310 Szczecin, Poland \\ ${ }^{2}$ Polymer Materials Technology Department, West Pomeranian University of Technology, Al. Piastów 17, \\ 70-310 Szczecin, Poland \\ ${ }^{3}$ Instituto de Estructura de la Materia, IEM-CSIC, Serrano 121, 28006 Madrid, Spain \\ ${ }^{4}$ Lukasiewicz Research Network - PORT Polish Center for Technology Development, ul. Stabłowicka 147, \\ 54-066 Wrocław, Poland
}

Received 8 May 2019; accepted in revised form 17 July 2019

\begin{abstract}
A series of aliphatic-aromatic copolyesters based on poly(butylene terephthalate) (PBT) and poly(lactic acid) (PLA) have been synthesized by means of a novel reactive blending procedure coupled with polycondensation in melt. The obtained copolymers were further compared with PBT and PLA homopolymers and PBT/PLA non-compatibilized physical blends in order to investigate the effect of transesterification reactions on the structural, morphological, thermal and mechanical performance. Properties of the obtained materials have been found strictly dependent on the preparation process and blend/copolymer composition. The PBT/PLA physical blends appeared as highly crystalline, phase separated systems that exhibit brittle behavior. On the other hand, the applied method of reactive blending enhanced interfacial adhesion and promoted the arrangement of PBT and PLA in blocks of different lengths. Although the PBT- $b$-PLA copolyesters were found to be miscible in amorphous phase, the phase separation that has arisen from PBT crystalline domains occurs. Along with an increase in PLA weight fraction in copolymers, the length of aromatic sequences decreased which in turn resulted in shifting the values of melting temperatures $\left(T_{\mathrm{m}}\right)$ toward lower ones and decreased the degree of crystallinity $\left(x_{\mathrm{c}}\right)$. Moreover, PBT- $b$-PLA copolymer with $30 \mathrm{wt} \%$ of PLA units has been demonstrated as a promising thermoplastic shape memory polymer (SMP) with a switching temperature of $35^{\circ} \mathrm{C}$.
\end{abstract}

Keywords: polymer blends and alloys, tailor-made polymers, block copolymers, material testing, shape memory polymers

\section{Introduction}

Owing to their excellent thermal and mechanical properties aromatic polyesters such as poly(ethylene terephthalate) (PET), poly(butylene terephthalate) (PBT) and poly(trimethylene terephthalate) (PTT) have been widely applied in packaging or textile industry and as engineering materials [1, 2]. Unfortunately, aromatic polyesters are highly resistant to degradation and remain stable over a long period of time, which is often an undesirable feature, in particular for short-term applications [3]. On the other hand, biodegradable aliphatic polyesters are generally characterized by poor thermal and mechanical performance $[1,4]$. In this view, the preparation of aliphatic-aromatic copolymers has been attracting considerable attention [5-8] as they may combine

${ }^{*}$ Corresponding author, e-mail: izabela.irska@zut.edu.pl (C) BME-PT 
mechanical performance of aromatic polyesters with biodegradability known from aliphatic ones. Currently, several petroleum-based biodegradable aliphaticaromatic copolymers with satisfactory mechanical properties are commercially produced. Among them, the most successful one is the poly(butylene adipateco-terephthalate) (PBAT) copolyester produced since the end of 1990s by BASF with the trademark of Ecofex ${ }^{\circledR}$ [7]. However, to meet the requirements of sustainable development, in recent years the application of renewable monomers in the production of polymers attracted significant attention from both academia and industry. The one that deserves special attention is lactic acid (LA) and its polymer, poly(lactic acid) (PLA), which is, so far, the most commercialized polymer being both derived from $100 \%$ renewable resources and biodegradable $[9,10]$. Owing to the number of advantages such as high tensile strength, transparency, and nontoxicity, PLA has been proposed as a leading bio-based candidate for a number of packaging and biomedical applications [10]. However, it is still a relatively rigid, brittle polymer with low thermal stability and low crystallization rate [10-13]. Therefore, in recent years a number of new PLA-based materials with improved characteristics have been prepared and studied. In this context, BASF launched new biodegradable polymeric material, that is a blend of aforementioned petrochemical-based Ecofex ${ }^{\circledR}$ with bio-based PLA (known under the trade name Ecovio ${ }^{\circledR}$ ) [7]. Ecovio ${ }^{\circledR}$ compounds contain an increased amount of renewable raw substrates and similarly to Ecoflex ${ }^{\circledR}$ are used in many different applications, such as compostable packing or mulch films, injection molding details and paper coatings [7]. Moreover, blends of PLA and highly crystalline polyesters, namely PBT have been extensively studied [14-16], as dispersed fast crystallizing phase may act as a nucleating agent for PLA, thus enhancing its crystallization kinetics. Although desirable combination of properties can be obtained by a simple and cost-effective blending of two or more polymers, the physical blends are phaseseparated systems and additional compatibilizer is required to enhance interfacial adhesion and compatibility between individual phases [17]. Some efforts were also made to improve the compatibility between PBAT and PLA [18-20].

An alternative approach to combine aromatic polyesters with aliphatic ones is the modification by either copolymerization or reactive blending.
Opaprakasit and coworkers [21, 22] synthesized poly(lactic acid-co-ethylene terephthalate) copolymers systematically from lactic acid, dimethyl terephthalate (DMT) and ethylene glycol (EG) via standard polycondensation method. The same synthesis route was applied by Namkajorn et al. [23] to study the effect of diols with various methylene lengths (ethylene glycol, 1,3-propanediol (PDO) and 1,4-butanediol (BD)) and monomer feed ratios on properties of lactic acid/terephthalate based copolyesters. Moreover, few efforts have been dedicated to the synthesis of aliphatic-aromatic copolymers via polycondensation starting from L-lactic acid oligomer (OLLA) and hydroxyl terminated poly(ethylene terephthalate) $[24,25]$, poly(butylene terephthalate) [26] or poly(trimethylene terephthalate) prepolymers [27]. More recently, due to the growing popularity of biobased aromatic furanic homologues, a few studies have been focused on copolymerization of PLA with poly(ethylene 2,5-furanodicarboxylate) (PEF) [28] and poly (butylene 2,5-furanodicarboxylate) (PBF) [29]. Special attention has been paid to the degradation studies of the above-mentioned systems. The obtained results reveal that one can enhance the degradability of aromatic polymer backbone by the incorporation of hydrolysable lactic acid units. Matos et al. [28] found that the amount of LA as low as $8 \mathrm{~mol} \%$ can substantially improve the degradability of PEF. However, from the preceding literature study, it was found that the prolonged two-step polymerization at high reaction temperature results in thermal degradation of poly(L-lactic acid) (PLLA) and formation of copolymers with random distribution along the copolymer chain. Only copolymers studied by Olewnik et al. [24] containing equimolar terephthalate/lactate ratio exhibited some block copolymer character. Furthermore, copolymers of PBT and PLLA as a major component (PLA- $b$-PBT$b$-PLA) with relatively defined blocky structure were synthesized via ring opening polymerization of LA with bis-(4-hydroxybutyl) terephthalate (BHBT) in solution [30]. Although this method promoted the organization into blocky structure, the obtained product exhibited very limited number average molecular weight $\left(M_{\mathrm{n}}\right)$ with a maximum value of $81.1 \mathrm{~g} / \mathrm{mol}$. Our objective was to overcome these limitations by implementing modified reactive melt blending procedure of PLA coupled with polycondensation of PBT, as an effective route of obtaining aliphatic-aromatic block copolymers. To the best of our knowledge, the 
melt processing method such as reactive blending has not been applied in the synthesis of lactic acid/ terephthalate based copolyesters to date. The latter technique has emerged as a promising approach to design polymers displaying original properties [3133]. There are two essential requirements to employ this method in copolymers synthesis: one is the immiscibility of polymer pair; the other is the presence of the groups able to react upon melt blending [34]. Both conditions are fulfilled in our system: (i) PBT and PLA are immiscible as verified by theoretical calculations; (ii) at high temperatures in polyesterpolyester blend three types of chemical reactions can occur, i.e. alcoholysis, acidolysis and ester exchange $[14,17,35]$. These chemical reactions lead to the formation of block or random copolymers. The chain structure can be controlled by the reaction temperature, blending time and the amount of catalyst.

In the present work two systems - physical blends and reactive blends of PBT/PLA have been prepared and compared with respect to their preparation process and resulting morphology. Thermodynamic immiscibility in PBT-PLA polymer pair was assessed, on the basis of algorithmic Hoy and Van Krevelen group contribution methods. The structure and properties of both series were characterized by means of attenuated total reflectance - Fourier transform infrared spectroscopy (ATR-FTIR), nuclear magnetic resonance spectroscopy $\left({ }^{1} \mathrm{H}\right.$ NMR), size exclusion chromatography (SEC), thermogravimetric analysis (TGA), differential scanning calorimetry (DSC), wide-angle X-ray scattering (WAXS), dynamic mechanical thermal analysis (DMTA) and scanning electron microscopy (SEM). Lastly, the related changes in tensile properties have been evaluated.

\section{Experimental section \\ 2.1. Materials}

The following chemicals were used for the copolymers' and blends' preparation: dimethyl terephthalate (DMT, Sigma-Aldrich, St. Louis, USA); tetramethylene glycol (1,4-butanediol, BASF SE, Ludwigshafen, Germany), tetrabutyl orthotitanate (TBT, Sigma-Aldrich, St. Louis, USA) as the transesterification and polycondensation accelerator. Phenolic antioxidant - pentaerythritol tetrakis (3-3,5-di-tert-butyl4-hydroxyphenyl propionate) under the trade name Irganox 1010 (Ciba-Geigy, Basel, Switzerland) was used to prevent thermal decomposition. PLA, Ingeo 4042 D grade (95.8\% LLA) with $M_{\mathrm{w}}=113000 \mathrm{~g} / \mathrm{mol}$ purchased from NatureWorks (Minnetonka, USA) was used, dried in-line for $12 \mathrm{~h}$ at $80^{\circ} \mathrm{C}$ prior to processing, in order to prevent any potential hydrolytic degradation.

\subsection{Synthesis (reactive blending) of PBT-b-PLA copolymers}

The synthesis process was carried on in $1 \mathrm{dm}^{3}$ steel reactor (Autoclave Engineers Pennsylvania, USA) equipped with a condenser, a stirrer and a gas inlet. The poly(butylene terephthalate) homopolymer was synthesized by a two-step melt polycondensation reaction (transesterification and polycondensation), according to the procedure described previously [36]. Poly(butylene terephthalate)-block-poly(lactic acid) (PBT- $b$-PLA) copolymers were prepared by modified reactive blending procedure (combination of polycondensation and reactive blending procedures), as follows. In the first step, the transesterification reaction was carried out at $160-165^{\circ} \mathrm{C}$. In the presence of the catalyst (TBT) DMT transesterifies with tetramethylene glycol (two-fold excess was used), the released methanol was distilled out of the reaction mixture at atmospheric pressure. Then, the temperature was increased slowly to $220^{\circ} \mathrm{C}$ and maintained for half an hour to reach the endpoint of transesterification (until $\sim 90 \%$ of the stoichiometric amount of by-product was released). The second step, the modified melt polycondensation of BHBT with PLA was carried out at a temperature of $235^{\circ} \mathrm{C}$, in the presence of the second portion of TBT catalyst and thermal stabilizer Irganox 1010. Process was conducted under reduced pressure of $25-30 \mathrm{~Pa}$, to facilitate the removal of 1,4-butanediol excess. During the polycondensation, the stirring torque changes were monitored to evaluate the viscosity of the product. All syntheses were finished when melt reached established value of viscosity at $230^{\circ} \mathrm{C}$ (30-60 $\mathrm{min}$ ). The molten materials were extruded from the reactor under compressed nitrogen and cooled down to room temperature in a water bath. PBT- $b$-PLA copolymers with different feed ratios of PBT to PLA $(90 / 10,80 / 20,70 / 30)$ were synthesized. Higher PLA content copolymers were studied, but the results are not reported herein since polymers with low molecular weight and poor mechanical properties were obtained. The copolymer samples were denoted as PBT- $b$-PLA 10 , PBT- $b$ PLA 20 and PBT- $b$-PLA 30, depending on the PLA weight percentage in feed. 


\subsection{Preparation of the physical PBT/PLA blends}

For the sake of comparison, PBT was melt blended with commercial PLA 4042 D in laboratory scale twin screw extruder (Laborextruder LSM30 L/D 22.9, Leistriz, Nürnberg, Germany) in the presence of a thermal stabilizer - Irganox 1010 (0.5 wt\%). Prior to compounding, both PBT and PLA were dried inline for $80^{\circ} \mathrm{C}$ for $12 \mathrm{~h}$. The optimum extrusion temperature was $240^{\circ} \mathrm{C}$, which is above the melting temperatures of both polymers. With the feeder output set to $1.5 \mathrm{~kg} / \mathrm{h}$ and a screw speed of $50 \mathrm{rpm}$, it took $\sim 5$ min for the material to pass from the feed section to the extruder nozzle. The extruded filament was quenched in a water bath. The PBT/PLA ratio was varied to obtain blends with 10,20 and $30 \mathrm{wt} \%$ of PLA (samples denoted as PBT/PLA 10, PBT/PLA 20 and PBT/PLA 30, respectively).

\subsection{Samples preparation}

The obtained materials were pelletized and injection molded to obtain dumbbell shape samples (A3 type) for further DMTA analysis and tensile tests. The optimal injection pressure was around $50 \mathrm{MPa}$ and the temperatures were $15^{\circ} \mathrm{C}$ higher than the melting point of the polymer determined by DSC. An injection molding machine (Dr. Boy GmbH \& Co., Neustadt-Fernthal, Germany) was employed.

\subsection{Measurements}

Attenuated total reflectance - Fourier transform infrared spectra of copolymers and blends were recorded using FT-IR spectrophotometer Tensor 27 (Bruker Optik GmbH, Ettingen, Germany) with 32 scans and a resolution of $2 \mathrm{~cm}^{-1}$.

The copolymers structure and molecular composition were determined by means of ${ }^{1} \mathrm{H}$ NMR spectroscopy. All samples were subjected to continuous Soxhlet extraction with methanol (Avantor Performance Materials Poland S.A., Gliwice, Poland) in order to remove unreacted monomer and any possible low molecular degradation products. ${ }^{1} \mathrm{H}$ NMR spectra were recorded at room temperature with Bruker spectrometer, operated at $400 \mathrm{MHz}$ (Bruker, Karlsruhe, Germany). The blends samples were dissolved in trifluoroacetic acid- $d$, while PBT- $b$-PLA copolymers samples were dissolved in trifluoroacetic acid- $d /$ chloroform- $d \quad \mathrm{CF}_{3} \mathrm{COOD} / \mathrm{CDCl}_{3}$ $(1: 3 \mathrm{v} / \mathrm{v})$ solvent mixture, both at the concentration of $10 \mathrm{mg} / \mathrm{ml}$.
Size exclusion chromatography in 1,1,1,3,3,3-hexafluoroisopropanol (HFIP, Sigma-Aldrich, St. Louis, USA) was performed at $40^{\circ} \mathrm{C}$, on a system equipped with a Waters 1515 Isocratic HPLC pump, a Waters 2414 refractive index detector $\left(35^{\circ} \mathrm{C}\right)$, a Waters 2707 autosampler and a PSS PFG guard column followed by two PFG-linear-XL $(7 \mu \mathrm{m}, 8 \times 300 \mathrm{~mm})$ columns in series (Waters, Milford, USA). HFIP with potassium trifluoroacetate $(3 \mathrm{~g} / \mathrm{l})$ was used as the eluent at a flow rate of $0.8 \mathrm{ml} / \mathrm{min}$. Calibration of the system was performed in relation to poly(methyl methacrylate) standards. The number average $\left(\bar{M}_{\mathrm{n}}\right)$ and weight average molecular weights $\left(\bar{M}_{\mathrm{w}}\right)$ and polydispersity index (PDI) were evaluated.

The intrinsic viscosity $[\eta]$ of polymer solutions was measured using capillary Ubbelohde'a type $1 \mathrm{c}(K=$ $0.03294)$ at $30 \pm 0.1{ }^{\circ} \mathrm{C}$. A polymer solution with a concentration of $0.5 \mathrm{~g} / \mathrm{dl}$ in the mixture of phenol/ 1,1,2,2-tetrachloroethane (60/40 by weight) (SigmaAldrich, St. Louis, USA) was used.

The density measurements were performed at $23^{\circ} \mathrm{C}$ on hydrostatic balance (Radwag AS160 C2, Radom, Poland), using distilled water as the immersion medium.

The morphology of copolymers and blends was observed with a scanning electron microscopy (JEOL JSM 6100, Freising, Germany) at an acceleration voltage of $1 \mathrm{kV}$. All samples were cryo-fractured in liquid nitrogen and coated with a thin homogenous gold layer by ion-sputtering to facilitate the measurements. The thermal properties of copolymers and blends were investigated using Mettler Toledo (Leicester, UK) differential scanning calorimeter under nitrogen atmosphere. Each DSC testing cycle consisted of heating-cooling and repeating the scans, with the heating/cooling rate of $10^{\circ} \mathrm{C} / \mathrm{min}$, from 0 to $250^{\circ} \mathrm{C}$. The results of the second heating run were used for the investigation. Glass transition temperature $\left(T_{\mathrm{g}}\right)$ was determined using midpoint approach, while the change in specific heat capacity $\left(\Delta C_{\mathrm{p}}\right)$ was calculated from the vertical distance between extrapolated baselines at the glass transition temperature. The crystallization $\left(T_{\mathrm{c}}\right)$ and melting $\left(T_{\mathrm{m}}\right)$ temperatures were determined from the maximum of the exothermic and endothermic peaks, respectively. The heat of fusion $\left(\Delta H_{\mathrm{m}}\right)$ and crystallization $\left(\Delta H_{\mathrm{c}}\right)$ were calculated from the total areas under melting and crystallization peaks on the DSC curve. The degree of crystallinity $\left(x_{\mathrm{c}}\right)$ was calculated from the enthalpy of fusion, according to Equation (1): 
$x_{\mathrm{c}}^{\mathrm{DSC}}=\left(\frac{\Delta H_{\mathrm{m}}-\Delta H_{\mathrm{cc}}}{\Delta H_{\mathrm{m}}^{0}} \cdot w_{\mathrm{PLA} / \mathrm{PBT}}\right) \cdot 100 \%$

where $\Delta H_{\mathrm{m}}$ is the heat of fusion estimated from the second heating scan, $\Delta H_{\mathrm{cc}}$, the correction due to heat of cold crystallization process, $\Delta H_{\mathrm{m}}^{0}$, the theoretical value of enthalpy for fully crystalline $\operatorname{PBT}\left(\Delta H_{\mathrm{m}_{\mathrm{PBT}}}^{0}=\right.$ $144.5 \mathrm{~J} / \mathrm{g}$ [37]) or PLA $\left(\Delta H_{\mathrm{m}}^{0}{ }_{\mathrm{PLA}}=93.7 \mathrm{~J} / \mathrm{g}[9]\right)$,

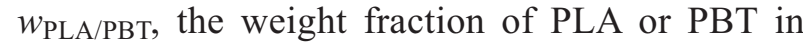
copolymer.

WAXS measurements of annealed samples were performed using X'Pert PRO diffractometer (PANalytical, Almelo, Netherlands) operating with $\mathrm{Cu} \mathrm{K} \alpha$ radiation $\left(\lambda=1.54 \AA\right.$ ) over a $2 \theta$ range of 5 to $40^{\circ}$, with a step of $0.05^{\circ}$.

Viscoelastic properties of PBT- $b$-PLA copolymers and blends were analyzed using dynamic mechanical analyzer (DMTA Q800, TA Instruments, New Castle, USA) working in dual cantilever mode. Temperature-dependent measurements of storage modulus $\left(E^{\prime}\right)$ and loss modulus $\left(E^{\prime \prime}\right)$ were performed at a fixed frequency of $1 \mathrm{~Hz}$, from -50 to $200^{\circ} \mathrm{C}$ at the heating rate of $3{ }^{\circ} \mathrm{C} / \mathrm{min}$. The DTMA results are expressed as storage modulus $\left(E^{\prime}\right)$ corresponding to the elastic response to the deformation and damping factor $(\tan \delta)$ versus temperature.

The shape memory properties (SMP) were monitored by means of cyclic thermo-mechanical analysis using the same DMTA apparatus, working in controlled strain mode. Polymer films of approximately $200 \mu \mathrm{m}$ thick were tested. The measurements were performed following the procedure described in detail by Xie et al. [38]. Eight consecutive cycles consisting of heating - stress loading - cooling - stress unloading - heating were conducted. Programming of SMP was carried out at $50^{\circ} \mathrm{C}\left(15^{\circ} \mathrm{C}\right.$ above calorimetric $T_{\mathrm{g}}$ ), while fixing of temporary shape was performed in $0{ }^{\circ} \mathrm{C}$. Constant heating and cooling rate of $10^{\circ} \mathrm{C} / \mathrm{min}$ was maintained. The shape fixity efficiency $\left(R_{\mathrm{f}}\right)$ and shape recovery $\left(R_{\mathrm{r}}\right)$ were determined for each cycle according to Equations (2) and (3), respectively:

$R_{\mathrm{Nf}}=\frac{\varepsilon_{\mathrm{N} 2}-\varepsilon_{\mathrm{N} 0}}{\varepsilon_{\mathrm{N} 1}-\varepsilon_{\mathrm{N} 0}} \cdot 100 \%$

$R_{\mathrm{Nr}}=\frac{\varepsilon_{\mathrm{N} 2}-\varepsilon_{(\mathrm{N}+1) 0}}{\varepsilon_{\mathrm{N} 2}-\varepsilon_{\mathrm{N} 0}} \cdot 100 \%$

where $\varepsilon_{\mathrm{N} 0}-$ the initial strain for the $N$ th cycle, $\varepsilon_{\mathrm{N} 1}-$ the maximum strain of stretched sample, $\varepsilon_{\mathrm{N} 2}-$ the fixed strain after unloading, $\varepsilon_{(\mathrm{N}+1) 0}-$ the strain after recovering, also stand for the initial strain of the successive cycle.

Thermogravimetric analysis was run under air atmosphere using the SETARAM TGA 92-16 thermal analyzer (Caluire-et-Cuire, France), from room temperature up to $700^{\circ} \mathrm{C}$, at a constant heating rate of $10^{\circ} \mathrm{C} / \mathrm{min}$. The thermal degradation temperatures at $5 \%$ mass loss $\left(T_{\mathrm{d}, 5 \%}\right)$ and the temperature of maximum mass loss $\left(T_{\mathrm{DTG}_{1}}, T_{\mathrm{DTG}_{2}}\right.$, and $\left.T_{\mathrm{DTG}_{3}}\right)$ were determined.

The tensile tests of the polymeric materials under investigation were performed using Autograph AG-X plus universal testing machine (Shimadzu, Tokyo, Japan), equipped with $1 \mathrm{kN}$ load cell, a TRViewX non-contact type video extensometer, and pneumatic rubber-coated grips. Measurements were controlled by TrapeziumX software. Stress-strain tests were performed at room temperature, with a crosshead speed of $1 \mathrm{~mm} / \mathrm{min}$ up to $1 \%$ of elongation and followed by $5 \mathrm{~mm} / \mathrm{min}$ to break. Tensile stress and elongation at break were evaluated from stress-strain data, Young's modulus was determined from the linear slope of the stress-strain curve (from 0.05 to $0.25 \%$ strain). To obtain a reliable average value and standard deviation at least seven samples were tested. Shore D hardness was measured using a Zwick 3100 Shore D tester (Zwick GmbH \& Co., Ulm, Germany). Each reported value is the mean of 10 independent measurements.

\section{Results and discussion}

\subsection{Synthesis and molecular characterization}

Multiblock copolymers with block distribution of PBT and PLA segments were synthesized by modified reactive melt blending procedure, concerning the introduction of PLA polymer into the PBT polycondensate. For comparison purposes, PBT/PLA physical blends were prepared by direct melt blending, in a laboratory extruder. The PLA content in the reaction mixture varied from 10 to $30 \mathrm{wt} \%$ (ca. 25 to $57 \mathrm{~mol} \%$ ) in both copolymers and blends (see Table 1). The as-synthesized copolymers are transparent, with light yellow color, the intensity of which increases progressively with PLA weight fraction. The reason of the polymer coloration might be related to increasing polycondensation time, resulting in thermal decomposition at high temperatures or due to the use of TBT as reaction catalyst, as explained by some authors $[39,40]$. In contrast, respective 
physical blends appear as opaque semi-crystalline solids.

To verify the molecular structure of physical blends and copolymers, set of ATR-FTIR and ${ }^{1} \mathrm{H}$ NMR investigations were performed. The ATR-FTIR spectra of parent polymers and representative spectra of PBT- $b$-PLA 30 copolymer are reported in Figure 1. For analyzed homopolymers, the asymmetric and symmetric stretching vibrations in $\mathrm{C}-\mathrm{H}$ bonds have been identified at 2954-2960 $\mathrm{cm}^{-1}$ (vibrations of $\mathrm{CH}_{2}$ groups of PBT) and 2945-2995 $\mathrm{cm}^{-1}\left(\mathrm{CH}_{3}\right.$ groups of PLA). Meanwhile, bending vibrations of $\mathrm{C}-\mathrm{H}$ bonds are located between 1360 and $1454 \mathrm{~cm}^{-1}$. The bands corresponding to $\mathrm{C}-\mathrm{O}, \mathrm{C}-\mathrm{O}-\mathrm{C}, \mathrm{C}=\mathrm{C}$ stretching

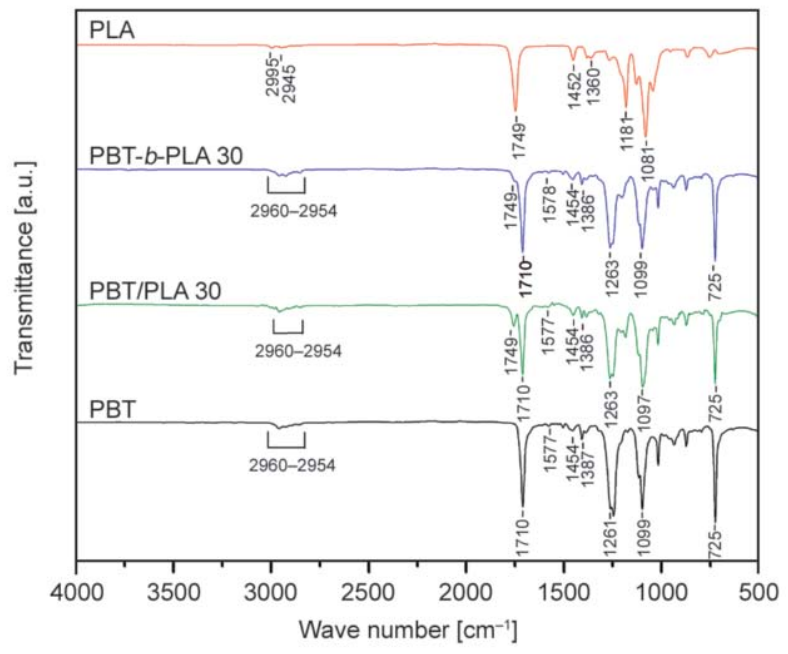

Figure 1. ATR-FTIR spectra of homopolymers, PBT/PLA 30 blend and PBT- $b$-PLA 30 copolymer. vibration are identified at $\sim 1260, \sim 1100$ and $\sim 1578 \mathrm{~cm}^{-1}$, respectively. The sharp peaks at 1710 and $725 \mathrm{~cm}^{-1}$ at PBT spectrum can be attributed to ester group $\mathrm{C}=\mathrm{O}$ stretching vibration and aromatic ring $\mathrm{C}-\mathrm{H}$ out-of-plane deformation, respectively. However, in PLA, the peak value corresponding to $\mathrm{C}=\mathrm{O}$ stretching is observed at $1749 \mathrm{~cm}^{-1}$. This peak position was reported as a special feature of aliphatic polyesters [23, 41]. At PBT/PLA blend and PBT- $b$ PLA copolymer spectra, most of the bands are located in the same or slightly shifted positions as PBT. In addition, at copolymer and blend spectra the weak peak at $1749 \mathrm{~cm}^{-1}$, typical for ester carbonyl $\mathrm{C}=\mathrm{O}$ groups of PLA, occur as a shoulder of the aromatic stretching $\mathrm{C}=\mathrm{O}$ band; thus, confirming successful incorporation of PLA moiety. Similar IR features were observed for all PBT/PLA blends and copolymers. As an example, the ${ }^{1} \mathrm{H}$ NMR spectra of PBT/PLA 30 blend and PBT-b-PLA 30 copolymer, together with the resonance assignments are shown in Figures 2 and 3, respectively. The ${ }^{1} \mathrm{H}$ NMR spectra of PBT/PLA physical blend can be considered as simple additive spectra of constituent homopolymers. Resonance signals corresponding to the four aromatic protons of terephthalate unit $(\mathrm{T})$ appear at $8.15 \mathrm{ppm}(\mathbf{c}$ signal), whilst those of outer and inner methylene protons of butylene unit (BG) appear at $4.56 \mathrm{ppm}$ $\left(-\mathrm{O}-\mathrm{CH}_{2}-\right.$, d signal $)$ and $2.08 \mathrm{ppm}\left(-\left(\mathrm{CH}_{2}\right)_{2}\right.$, e signal). The lactide repeating unit (LA) gives a doublet at $1.68 \mathrm{ppm}$ (a signal) and a quadruplet at $5.38 \mathrm{ppm}$

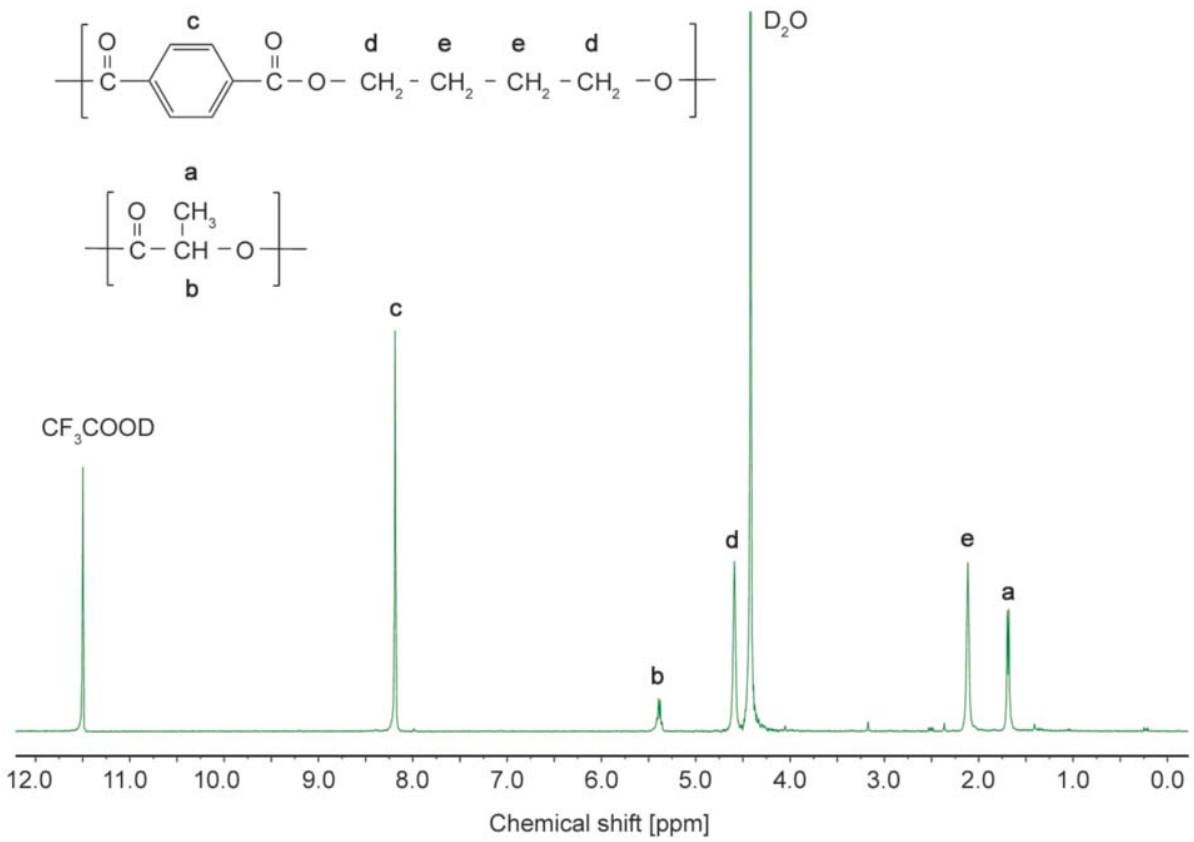

Figure 2. ${ }^{1} \mathrm{H}$ NMR spectrum of PBT/PLA 30 blend. 
(b signal) arising from methyl $\left(-\left(\mathrm{CH}_{3}\right)-\right)$ and methine (-CH-) groups, respectively.

As shown in Figure 3, signals characteristic for polymer blends are also evident at copolymer spectra. In addition, weak signals specific for LA methyl (signal $\mathbf{a}^{\prime}$ ) and methine (signal $\mathbf{b}^{\prime}$ ) chain-end groups appear at lower chemical shift with respect to the same resonances observed for LA chain unit (zoomed views at Figure 3). This phenomenon can be reasonably ascribed to the partial degradation of PLA to lactic acid oligomer (OLA) upon reactive blending at high temperature. Moreover, significant differences in methylene group proton region of copolymer spectra can be seen. This is due to the transesterification reaction between the carboxyl groups of T-BG units and terminal hydroxyl groups of PLA, which led to the formation of new ester linkages. As a consequence, BG unit protons are located in different environments (adjacent to T or LA unit) and additional resonance signals at copolymer spectra at $4.30-4.60 \mathrm{ppm}$ (-O-C $\mathrm{CH}_{2-}$, d signals) and $1.95-2.45 \mathrm{ppm}\left(-\left(\mathrm{CH}_{2}\right)_{2}-\right.$, e signals) occur. To better understand the nature of the sequence distribution along the copolymer chain, the analysis of possible BG-centered triads has to be considered. Zoomed view of the spectra (region of methylene groups) together with detailed BG unit peak assignments under interest are shown in Figure 4. It is obvious that the sequences present in PBT homopolymer, T-BG-T are also evident in copolymer chain. In addition, two other sequences T-BG-LA (LA-BG-T) and LA-BG-LA can be identified. At
PBT- $b$-PLA spectra resonance signals of methylene protons of BG subunit adjacent to $\mathrm{T}$ units (T-BG-T triad) appear at $4.70 \mathrm{ppm}\left(\mathbf{d}_{\mathbf{1}}\right.$ signal) and $2.22 \mathrm{ppm}$ (e $\mathbf{e}_{1}$ signal). Furthermore, new signals arising from mixed sequences (T-BG-LA or LA-BG-T) were distinguished at $4.64 \mathrm{ppm}\left(-\mathrm{O}-\mathrm{CH}_{2}-, \mathbf{d}_{2}\right.$ signal), $4.55 \mathrm{ppm}\left(-\mathrm{O}-\mathrm{CH}_{2}-, \mathbf{d}_{3}\right.$ signal $)$ and $2.10 \mathrm{ppm}$ $\left(-\left(\mathrm{CH}_{2}\right)_{2}-, \mathbf{e}_{2}\right.$ signal $)$. Lastly, the weak resonance signals corresponding to outer and inner methylene protons of BG unit assigned to LA-BG-LA triad occur at $4.51 \mathrm{ppm}\left(\mathbf{d}_{4}\right.$ signal $)$ and $2.00 \mathrm{ppm}\left(\mathbf{e}_{3}\right.$ signal), respectively.

The arrangement of building blocks along copolymer chain has a great influence on the final physical properties of copolymer. According to the approach introduced by Yamadera and Murano [42] from the relative intensities of methylene signals of BG unit, the number-average sequence length of terephthalate unit $\mathrm{L}_{\mathrm{T}}$, lactate unit $\mathrm{L}_{\mathrm{LA}}$ and the degree of randomness $\mathrm{B}$ around the $\mathrm{BG}$ unit can be estimated using Equations (4)-(6), respectively:

$$
\begin{aligned}
& \mathrm{L}_{\mathrm{LA}}=\frac{\frac{I_{\mathrm{T}-\mathrm{BG}-\mathrm{LA}}+I_{\mathrm{LA}-\mathrm{BG}-\mathrm{T}}}{2}+I_{\mathrm{LA}-\mathrm{BG}-\mathrm{LA}}}{\frac{I_{\mathrm{T}-\mathrm{BG}-\mathrm{LA}}+I_{\mathrm{LA}-\mathrm{BG}-\mathrm{T}}}{2}} \\
& \mathrm{~L}_{\mathrm{T}}=\frac{\frac{I_{\mathrm{T}-\mathrm{BG}-\mathrm{LA}}+I_{\mathrm{LA}-\mathrm{BG}-\mathrm{T}}}{2}+I_{\mathrm{T}-\mathrm{BG}-\mathrm{T}}}{\frac{I_{\mathrm{T}-\mathrm{BG}-\mathrm{LA}}+I_{\mathrm{LA}-\mathrm{BG}-\mathrm{T}}}{2}} \\
& \mathrm{~B}=\frac{1}{\mathrm{~L}_{\mathrm{LA}}}+\frac{1}{\mathrm{~L}_{\mathrm{T}}}
\end{aligned}
$$
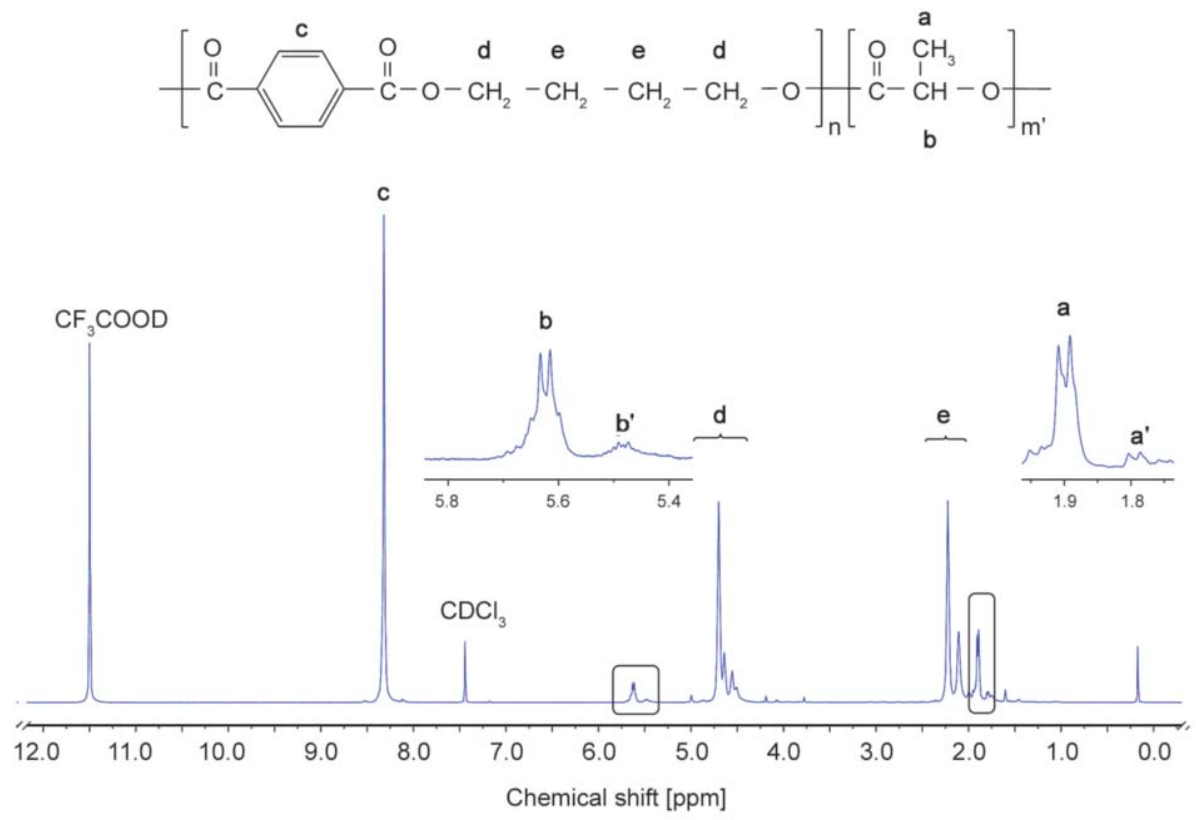

Figure 3. ${ }^{1} \mathrm{H}$ NMR spectrum of PBT- $b$-PLA 30 copolymer. 


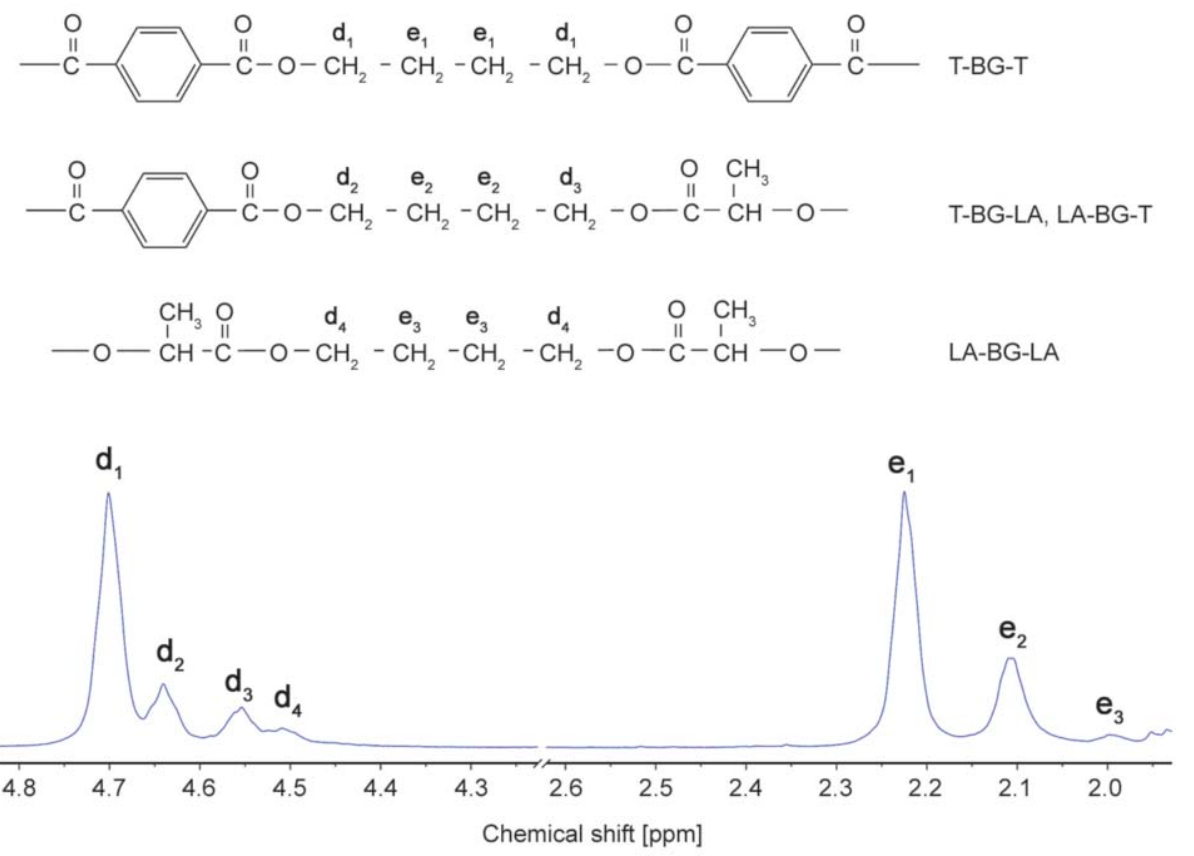

Figure 4. Zoomed view of the copolymer spectra together with detailed BG unit peak assignments $\left({ }^{1} \mathrm{H}\right.$ NMR spectrum of PBT-b-PLA 30).

where $I_{\text {T-BG-LA }}, I_{\text {LA-BG-T }}, I_{\text {LA-BG-LA }}, I_{\text {T-BG-T }}$ represent the integrated intensities of butylene proton resonance signals of T-BG-LA, LA-BG-T, LA-BG-LA, and T-BG-T sequences, respectively. The obtained results are given in Table 1. The sequential length and B were calculated on the basis of $\mathbf{d}$ group of butylene protons signals (in the range of $4.8-4.4 \mathrm{ppm}$ ). It can be observed that the sequence length is proportional to the contribution of individual co-units in copolymer. $\mathrm{L}_{\mathrm{T}}$ regularly decreases from 12.13 to 5.20 , as the weight fraction of PLA increase from 10 to $30 \%$. Consequently, as the amount of LA units increase, an increment of $\mathrm{L}_{\mathrm{LA}}$ can be noticed. Slight increase of $\mathrm{L}_{\mathrm{LA}}$ from 1.26 to 1.38 was observed suggesting that the LA units are rather short, irrespective of the initial composition. Anyway, all copolymers exhibit B value bellow 1, pointing out that T, BG and LA units tend to form block copolymers under reactive melt blending process $[6,43]$. Being more precise, short-block copolymers were obtained $(B>0.65)$ [6]. A slight increase in the degree of randomness with PLA concentration in copolymer can be a consequence of prolonged reaction time, which favors the redistribution (transesterification) reactions [6, 44]. These sequence distribution observations are of primary importance as regards to the biodegradability of copolymers. Several results suggested that higher degradation rate would be achieved, if not only biodegradable segments are incorporated but also shortening of aromatic sequences can facilitate this process $[8,45]$.
Biodegradation studies on these copolymers will be the subject of the forthcoming work.

The actual content of each unit was calculated from the relative areas of the ${ }^{1} \mathrm{H}$ NMR resonance peaks attributed to the aromatic protons of the PBT moiety at $\delta \sim 8.14-8.16 \mathrm{ppm}$ and the methine proton of the PLA moiety at $\delta \sim 5.40-5.73 \mathrm{ppm}$. Table 1 reports the detailed composition data of reaction mixtures, the obtained copolymers, and blends. In all resulting copolymers, the significant decrease in PLA concentration can be observed, even up to $30 \%$ of the feed content, while in the case of investigated physical blends the actual composition is nearly equal to the feed one. The reduced amount of PLA in the resulting copolyester can be related with, firstly, the oligomer distillation under reduced pressure and secondly, the PLA thermal decomposition during the melt polycondensation at high temperature. The authors attribute these effects to the degradation of PLA to lactic acid oligomers rather than the distillation of the reaction substrates since the pressure in the reactor was lowered gradually and a clear liquid distillate was obtained. Moreover, the presence of a small amount of OLA in the obtained material has also been verified with the ${ }^{1} \mathrm{H}$ NMR investigations. Similar phenomenon has been reported for other aromatic-lactic acid copolymers, such as poly(ethylene-terephthalate)-co-poly (lactic acid) [24], poly(ethylene-2,4-furanodicarboxylate)-co-poly(lactic acid) [28] and poly(butylene-2,4furanodicarboxylate)-co-poly(lactic acid) [29]. 
Table 1. Composition, molecular characterization, and density of investigated homopolymers, copolymers, and PBT/PLA physical blends.

\begin{tabular}{|c|c|c|c|c|c|c|c|c|c|c|c|}
\hline Sample & $\begin{array}{c}\text { PBT/PLA feed ratio } \\
\text { [wt } \%]\end{array}$ & $\begin{array}{l}\text { PLA }^{\mathrm{b}} \\
{[\mathbf{w t} \%]}\end{array}$ & $\begin{array}{c}\text { PLA }^{\mathrm{b}} \\
{\left[\mathrm{mol}^{\circ} \mathrm{o}\right]}\end{array}$ & $\mathbf{L}_{\mathbf{T}}$ & $\mathbf{L}_{\mathbf{L}}$ & B & $\begin{array}{c}{[\mathrm{I \eta}]} \\
{[\mathrm{dl} / \mathrm{g}]}\end{array}$ & $\begin{array}{c}\overline{M_{\mathrm{n}}} \\
{\left[\mathrm{g} \cdot \mathbf{m o l}^{-1}\right]}\end{array}$ & $\begin{array}{c}\overline{\bar{M}_{\mathrm{w}}} \\
{\left[\mathrm{g} \cdot \mathbf{m o l}^{-1}\right]}\end{array}$ & PDI & $\begin{array}{c}d \\
{\left[\mathrm{~g} / \mathrm{cm}^{3}\right]}\end{array}$ \\
\hline PBT & $100 / 0$ & 0 & 0 & - & - & - & 1.31 & 33991 & 83577 & 2.46 & 1.307 \\
\hline PBT/PLA 10 & $90 / 10$ & 10.30 & 25.97 & - & - & - & 0.92 & 28510 & 71864 & 2.52 & 1.293 \\
\hline PBT/PLA 20 & $80 / 20$ & 19.85 & 43.08 & - & - & - & 1.01 & 31123 & 82053 & 2.64 & 1.275 \\
\hline PBT/PLA 30 & $70 / 30$ & 30.05 & 56.77 & - & - & - & 1.06 & 31448 & 90162 & 2.87 & 1.260 \\
\hline PBT- $b$-PLA 10 & $90 / 10$ & 4.22 & 11.86 & 12.13 & 1.26 & 0.88 & 0.97 & 32156 & 90205 & 2.81 & 1.302 \\
\hline PBT- $b$-PLA 20 & $80 / 20$ & 7.78 & 20.49 & 8.03 & 1.31 & 0.89 & 0.95 & 29689 & 72795 & 2.45 & 1.294 \\
\hline PBT-b-PLA 30 & $70 / 30$ & 13.12 & 31.58 & 5.20 & 1.38 & 0.92 & 0.92 & 26488 & 81982 & 3.10 & 1.291 \\
\hline PLA & $0 / 100$ & 100 & 100 & - & - & - & 1.64 & - & $113000^{*}$ & - & 1.244 \\
\hline
\end{tabular}

${ }^{a}$ in reaction mixture (feed), bin resulting copolymer/blend determined by ${ }^{1} \mathrm{H} N M R, \mathrm{~L}_{\mathrm{T}}-$ sequence length of terephthalate unit, $\mathrm{L}_{\mathrm{L}}-$ sequence length of lactate unit, B - degree of randomness, $[\eta]$ - intrinsic viscosity; $\overline{M_{\mathrm{n}}}, \overline{M_{\mathrm{w}}}-$ number and weight average molecular weight determined by GPC analysis, respectively, PDI - polydispersity index, $d$ - density, ${ }^{*}$ as stated by the manufacturer.

The influence of different feed ratios on intrinsic viscosity, GPC and density results are also shown in Table 1. Since PLA units with higher molecular weight were incorporated, an increase in copolymer molecular weight would be expected but was not observed. $\overline{M_{\mathrm{n}}}$ slightly decreases with increasing PLA content in the copolymer series: from $33991 \mathrm{~g} \cdot \mathrm{mol}^{-1}$ for PBT to $26488 \mathrm{~g} \cdot \mathrm{mol}^{-1}$ for PBT- $b$-PLA 0 , and their polydispersity index (PDI) ranged from 2.45 to 3.1. The adopted strategy of the incorporation of PLA polymer into PBT polycondensate appeared as a promising strategy for facile copolymer synthesis. Moreover, additional solid state polycondensation (SSP) can promote the chain growth to obtain improved final product [46]. It is worth highlighting that $\overline{M_{\mathrm{n}}}$ values are much higher than the ones reported in work by Zhu et al. [30] on similar PLA- $b$-PBT$b$-PLA copolymers with high PLA content. In contrast to the materials prepared by reactive blending, an increasing trend in molecular weight change in the PBT/PLA blend series was found. Along with an increase in PLA weight fraction in physical blend higher $\overline{M_{\mathrm{n}}}$ is observed, which is in agreement with the additivity rules. Moreover, the intrinsic viscosity values correlate well with molecular weight changes in both series. The densities of copolymers and blends are fitted between those of the two homopolymers, decreasing slightly as the PLA content increase.

\subsection{Theoretical investigation on miscibility of PBT-PLA systems}

One of the most characteristic features of block copolymers is that they exhibit a multiphase structure, resulting from micro and nanophase separation of incompatible blocks after cooling from the molten state. The tendency to form heterogeneous structure depends on polymer-polymer miscibility and can be predicted according to their solubility parameters. Numerous studies have confirmed the validity of Hoy approach in determining miscibility between two polymers [47-49]. A similar comprehensive approach has been proposed by Hoftyzer and Van Krevelen [50]. In both methods the total solubility parameter $\left(\delta_{t}\right)$ is based on structural contributions which are divided into three components resulting from dispersion forces $\left(\delta_{\mathrm{d}}\right)$, polar interaction $\left(\delta_{\mathrm{p}}\right)$ and hydrogen bonding $\left(\delta_{\mathrm{h}}\right)$ as described by Equation (7):

$\delta_{\mathrm{t}}^{2}=\delta_{\mathrm{d}}^{2}+\delta_{\mathrm{p}}^{2}+\delta_{\mathrm{h}}^{2}$

The values of $\delta_{\mathrm{t}}, \delta_{\mathrm{d}}, \delta_{\mathrm{p}}$ and $\delta_{\mathrm{h}}$ for both methods were calculated from a set of additive molar attraction constants, base values and molar volume values following data and algorithms proposed by Hoy and Hoftyzer-Van Krevelen [50]. To describe the miscibility between PBT and PLA the $\Delta \delta$ parameter was calculated using Equation (8):

$$
\Delta \delta=\left[\left(\delta_{\mathrm{d} 2}-\delta_{\mathrm{d} 1}\right)^{2}+\left(\delta_{\mathrm{p} 2}-\delta_{\mathrm{p} 1}\right)^{2}+\left(\delta_{\mathrm{h} 2}-\delta_{\mathrm{h} 1}\right)^{2}\right]^{1 / 2}
$$

The characteristic solubility parameters calculated for PBT, PLA and $\Delta \delta_{\text {PBT-PLA }}$ are listed in Table 2. It has been well established in the literature that the smaller the difference in solubility of two compounds is, the more miscible they are. Van Krevelen stated that pairs with $\Delta \delta \leq 5 \mathrm{MPa}^{1 / 2}$ are likely to be mutually soluble. Hoy and Hoftyzer-Van Krevelen methods are of the same order of accuracy and the optimal way for estimation of the solubility parameter is to 
apply both, taking the average results [50]. The obtained values of $\Delta \delta$ differ between the two methods $\left(\delta_{\text {PBT-PLA }}=4.73\right.$ and $\Delta \delta_{\text {PBT-PLA }}=9.66$ according to Hoy and Hoftyzer-Van Krevelen, respectively), giving

Table 2. Solubility parameters calculated by using Hoy and Hoftyzer-Van Krevelen group contribution methods.

\begin{tabular}{|l|c|c|c|c|}
\hline \multirow{2}{*}{$\begin{array}{c}\text { Solubility } \\
\text { parameters }\end{array}$} & \multicolumn{2}{|c|}{ Hoy } & \multicolumn{2}{c|}{ Hoftyzer-Van Krevelen } \\
\cline { 2 - 5 } & $\begin{array}{c}\text { PLA } \\
{\left[\mathbf{M P a}^{\mathbf{1} 2}\right]}\end{array}$ & $\begin{array}{c}\text { PBT } \\
{\left[\mathbf{M P a}^{\mathbf{1} / 2}\right]}\end{array}$ & $\begin{array}{c}\text { PLA } \\
\left.\mathbf{M P a}^{\mathbf{1} 2}\right]\end{array}$ & $\begin{array}{c}\text { PBT } \\
{\left[\mathbf{M P a}^{\mathbf{1} / 2}\right]}\end{array}$ \\
\hline$\delta_{\mathrm{t}}$ & 23.77 & 21.77 & 23.33 & 21.56 \\
\hline$\delta_{\mathrm{p}}$ & 15.61 & 11.94 & 14.94 & 5.87 \\
\hline$\delta_{\mathrm{h}}$ & 11.66 & 9.42 & 9.28 & 9.13 \\
\hline$\delta_{\mathrm{d}}$ & 13.61 & 15.58 & 15.33 & 18.64 \\
\hline$\Delta \delta_{\text {PBT-PLA }}$ & \multicolumn{2}{|c|}{4.73} & \multicolumn{2}{|c|}{9.66} \\
\hline
\end{tabular}

$\delta_{\mathrm{t}}-$ total solubility parameter, $\delta_{\mathrm{d}}-$ dispersion forces, $\delta_{\mathrm{p}}-$ polar interaction, $\delta_{\mathrm{h}}-$ hydrogen bonding, $\Delta \delta_{\text {PBT-PLA }}-$ miscibility parameter for PBT and PLA polymer pair

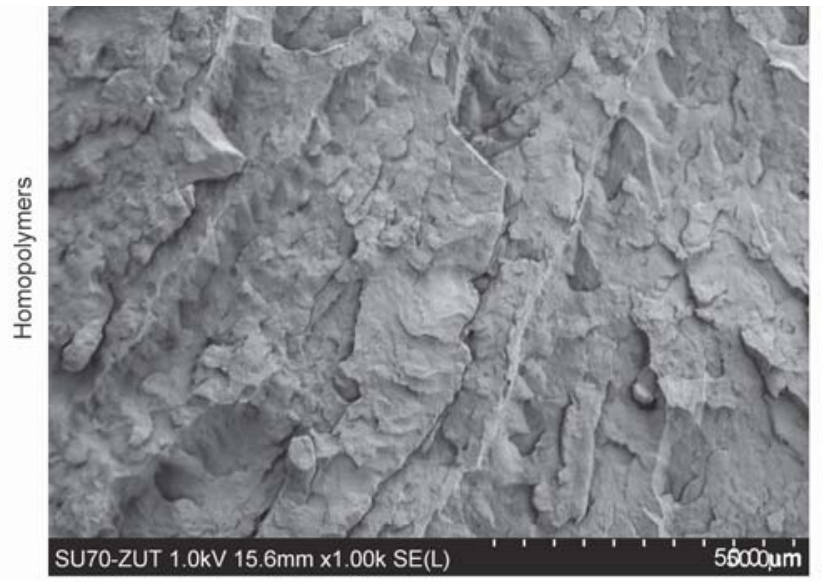

a)

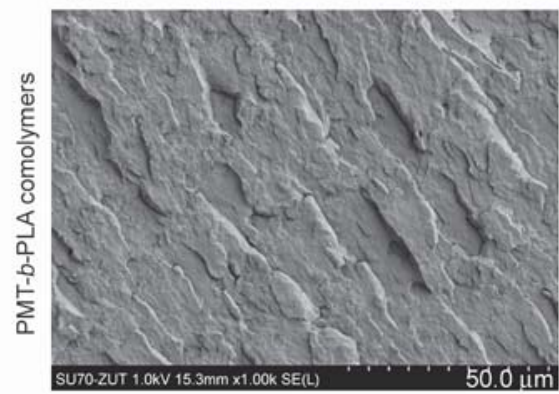

c1)

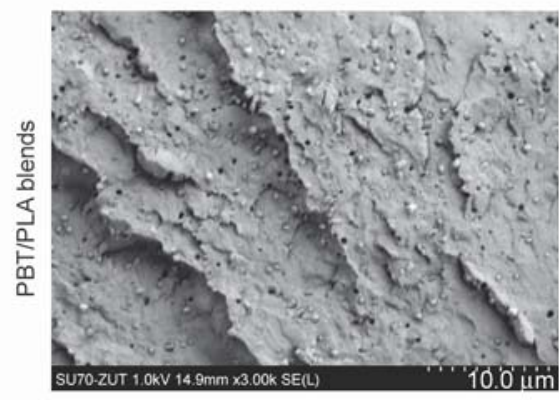

d1)

c2)

d2) an average of $7.20 \mathrm{MPa}^{1 / 2}$ which is slightly higher than $\Delta \delta$ parameter appointed for mutually miscible systems. Following this criterion, one can predict immiscibility in PBT-PLA systems. Nevertheless, calculations based on theoretical group contribution methods might provide rather rough estimates since crystallinity and average sequence length of building blocks are not taken into account [51]. Thus, these aspects have to be considered in further investigations.

\subsection{Morphology}

SEM microstructure analysis provided visual information about the morphology and the internal structure of investigated materials (see Figure 5). All homopolymers (Figure 5a and 5b) and copolymers (Figure $5 \mathrm{c} 1-5 \mathrm{c} 3$ ) exhibit uniform, homogenous fracture

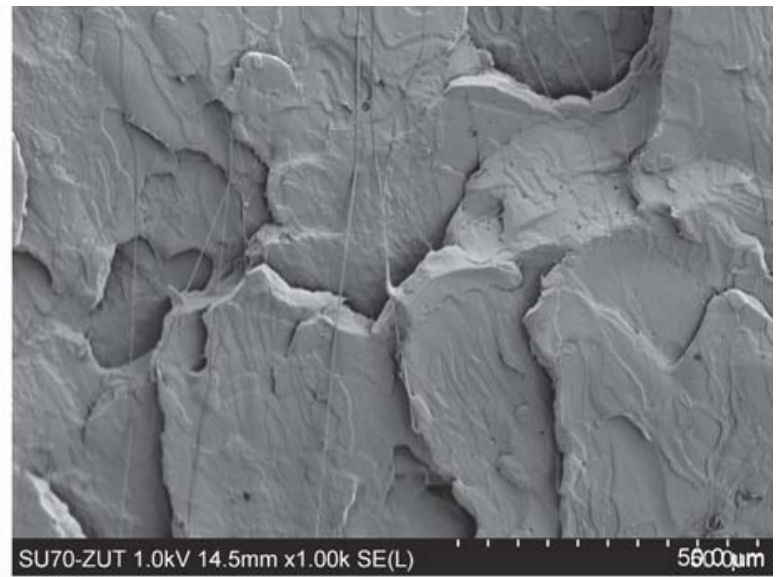

b)
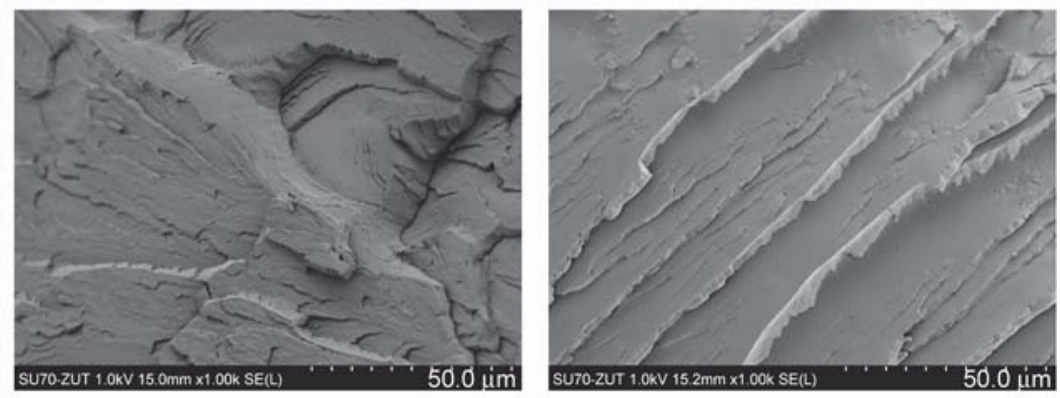

c3)

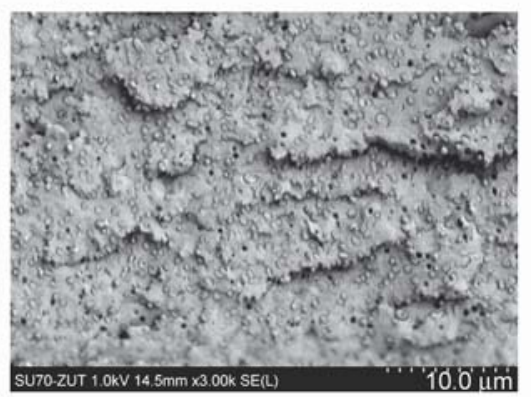

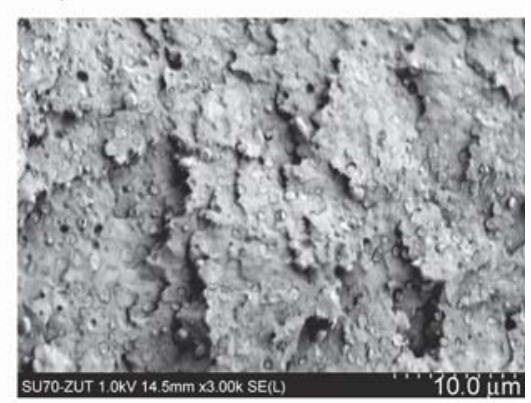

d3)

Figure 5. SEM micrographs of homopolymers: PBT (a) and PLA (b), copolymers and blends at different feed ratio, PBT- $b$ PLA 10 (c1), PBT-b-PLA 20 (c2), PBT-b-PLA 30 (c3), PBT/PLA 10 (d1), PBT/PLA 20 (d2), PBT/PLA 30 (d3). 
surface. However, the more PLA is incorporated into PBT backbone, the smoother PLA-like morphology is observed, indicating the increase of interfacial tension between components and copolymer formation during reactive blending. On the contrary, polymer blends (Figure 5d1-5d3) exhibit rougher, irregular surface, with two phases forming clearly separated domains. As stated previously, PBT/PLA blend may be classified as rather incompatible. As such, the physical blending of PBT with PLA resulted in typical droplet-matrix morphology, in which PBT constitutes the continuous matrix and PLA minor phase is randomly dispersed as spherical domains throughout the sample. Moreover, empty voids visible on cryofracture surface are a clear suggestion of weak interfacial adhesion between the two phases. This fracture morphology is similar to the appearance of noncompatibilized PBT/PLA blends reported by Samthong et al. [16].

\subsection{Thermal and structural characterization}

Calorimetric curves of investigated materials are shown in Figures $6 \mathrm{a}$ ( $2^{\text {nd }}$ heating) and $6 \mathrm{~b}$ (cooling), whereas the important numerical values are summarized in Table 3. On the basis of the second heating scan, one can assume that PBT exhibits the semicrystalline nature, while PLA demonstrates amorphous nature. However, it is important to clarify at this point, that PLA used in the present study is intrinsically semicrystalline, as evidenced by melting behavior at first heating scan (added at Figure 6a for sake of comparison) and further X-ray investigations (see Figure 7). Herein, the cooling scans were conducted at a rate of $10^{\circ} \mathrm{C} / \mathrm{min}$; thus, slow crystallizing PLA was not able to crystallize fast enough and did not show any melting peak at the $2^{\text {nd }}$ heating scan.

The investigated polymer blends appear as semi-crystalline, phase separated systems, where two forms of crystallites coexist, as revealed by the existence of distinct melting peaks, occurring at stable temperature irrespective of composition. The melting transition of the PLA phase occurs in the temperature range of $140-155^{\circ} \mathrm{C}$, and is followed by another endothermic event with maxima at ca. $223^{\circ} \mathrm{C}$ that corresponds to the melting point of $\mathrm{PBT}$ phase, both appeared as bimodal. This observation is common in both PLA and PBT and has been previously ascribed to the melting-recrystallization mechanism (perfection of the crystals during heating) [12, 52]. It is also consistent with melting behavior of PBT/PLA blends having a high content of PLA $[16,17]$. The melting temperatures of PBT and PLA remain almost stable in the whole composition range, while the intensity of the observed transitions correlates well with blend composition. Namely, increasing the weight content of PLA in PBT/PLA blend results in the decrease in melting enthalpy $\left(\Delta H_{\mathrm{mPBT}}\right)$ of PBT phase and coincident increase in enthalpy of both, cold crystallization $\left(\Delta H_{\mathrm{cc}}\right)$ and melting $\left(\Delta H_{\mathrm{mPLA}}\right)$ in PLA phase (see Table 3). Moreover one additional broad exothermic peak above $100^{\circ} \mathrm{C}$ occur at the heating scan, which can be confidently assigned to cold crystallization of PLA [16]. Although blending with PBT promotes the cold-crystallization of slow crystallizing PLA during heating scan, the estimated degree of crystallinity of the latter is rather insignificant from the quantitative point of view, exhibiting the highest value of $2.5 \%$ for PBT/PLA 30 sample. In turn, relatively fast crystallizing PBT exhibits crystallinity degree of $28.7 \%$, which remains almost unaltered by blending with PLA. The lowest $x_{\mathrm{CPBT}}$ of $26.0 \%$ was obtained for PBT/PLA 20 blend. Moreover, the cooling scans (Figure $6 \mathrm{~b}$ ) reveal that the overall crystallization rate of PBT was substantially enhanced, due to the presence of PLA. The crystallization peak temperatures determined during cooling from the melt $\left(T_{\mathrm{c}}\right)$ are higher, by $11-12{ }^{\circ} \mathrm{C}$ compared to PBT $\left(184^{\circ} \mathrm{C}\right)$, while a crystallizability expressed as the degree of supercooling, $\Delta T=T_{\mathrm{m}}-T_{\mathrm{c}}$ decreases (i.e., crystallization rate increases [53]) in the order of PBT $<$ PBT/PLA $30<$ PBT/PLA $20<$ PBT/PLA 10, exhibiting values of $39.4,28.9,27.5,27.1^{\circ} \mathrm{C}$, respectively. According to Ou et al. [54], crystallization acceleration phenomenon in PBT may be attributed to the nucleating effect of component that is in the minority in polymer blend.

As far as the PBT- $b$-PLA copolymers are concerned, it is reasonable to expect some evolution in crystallization behavior, due to the occurrence of transesterification reactions and PBT chain length variations $[6,23,33,55]$. At the thermograms of the second heating, single melting phenomenon originating from PBT component is clearly evident. With an increase in PLA feed content, the endotherm broadens and progressively shifts to lower temperature. Specifically, the $T_{\mathrm{m}}$ values decreased from 223.4 to $160.5^{\circ} \mathrm{C}$, whilst $\Delta H_{\mathrm{m}}$ decreased from 41.4 to $22.2 \mathrm{~J} / \mathrm{g}$ for neat PBT and $30 \%$ of initial PLA wt $\%$ content, respectively. Moreover, a very different DSC heating curve was recorded for the latter, exhibiting additional 

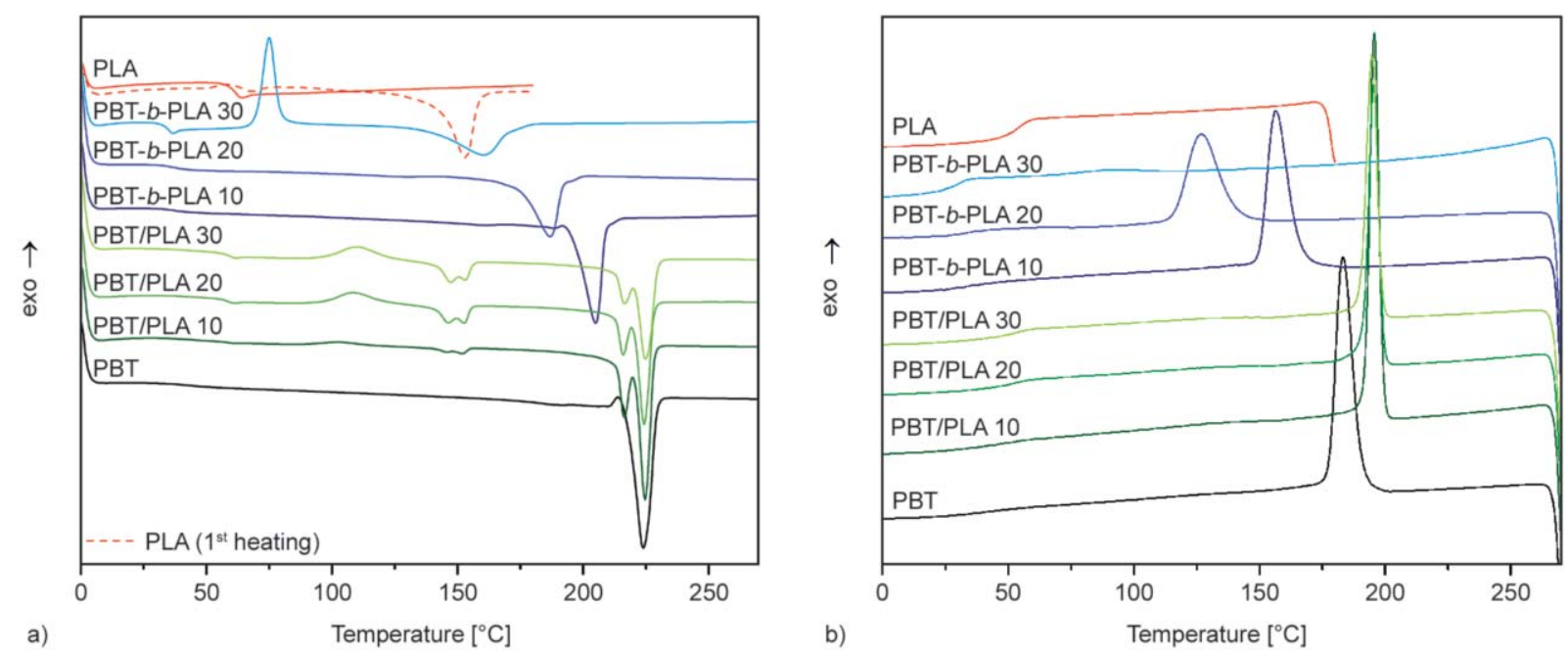

Figure 6. DSC thermograms of homopolymers, copolymers, and physical blends, recorded at heating/cooling rate of $10^{\circ} \mathrm{C} / \mathrm{min}$ : (a) $2^{\text {nd }}$ heating, (b) cooling.

exothermal cold-crystallization $\left(T_{\mathrm{cc}}\right)$ phenomenon during heating scan, with the maximum at $75.1^{\circ} \mathrm{C}$, seemingly similar to the one studied in physical blends but detected at significantly lower temperature and originating from cold crystallization of BG-T units rather than LA co-units. Furthermore, the $\Delta H_{\mathrm{cc}}$ peak area compares well with the $\Delta H_{\mathrm{m}}$ peak area, both exhibiting value of $22.2 \mathrm{~J} / \mathrm{g}$, thereby suggesting that the PBT-b-PLA 30 copolymer can be considered as non-crystallizing material, on fast cooling rates, typically applied in DSC analysis. From Table 3 it can be found that the $x_{\mathrm{CPBT}}$ values decrease along with increasing content of PLA co-unit. The estimated $x_{\mathrm{CPBT}}$ is $28.7 \%$ for neat PBT and decrease to 23.3, 20.5 and $0 \%$ for PBT- $b$-PLA 10 , PBT- $b$-PLA 20 , PBT- $b$-PLA 30, respectively. Moreover, reported values are much smaller than $x_{\mathrm{c}}$ of PBT phase in the physical blends. This phenomenon can be explained by the decrease in PBT block length and subsequent increase in the degree of randomness (that was confirmed in the molecular characterization section). Consequently, the PBT crystal formation was disturbed and less perfect crystallites with larger distributions were formed. The thermal effects originating from PLA cold crystallization or melting were not observed on heating scans, suggesting that crystalline phase of PLA had not been created in copolymers systems. As to the copolymers crystallization behavior (Figure $6 \mathrm{~b}$ and Table 3 ), an analogous trend to that detected in heating scan can be observed. As PLA content increases ( $\mathrm{L}_{\mathrm{T}}$ decreases), $T_{\mathrm{c}}$ shifting to the lower temperature, broadening and finally crystallization signal disappearing can be observed.
In all investigated systems single glass transition phenomenon $\left(T_{\mathrm{g}}\right)$ occurs after quenching from the melt. In physical blends, the $T_{\mathrm{g}}$ was detected at $\sim 58^{\circ} \mathrm{C}$, possibly as a result of overlapping transitions occurring in close proximity to one another, at 61.2 and $51.9^{\circ} \mathrm{C}$ in PLA and PBT phase, respectively. On the other hand, single $T_{\mathrm{g}}$ phenomenon can be associated with partial miscibility of non-crystallized phase of both PBT and PLA, that is more plausible in reactive blends. Interestingly, when reactive melt blending was carried on, the glass transition strongly decreased to $\sim 35^{\circ} \mathrm{C}$. This abnormal depression seems to be a result of chain flexibility and mobility provided by incorporation of short PLA aliphatic chains and reduced overall crystallinity. In the studied copolymers the contribution of restrictive crystalline domains gradually decreases, since PLA crystallites cannot be created anymore and PBT crystallizes weakly. Thus, the segmental motion of amorphous chains are not restricted by crystalline domains acting as net points [56] and glass transition temperature tends to decrease. Similar effect has been observed previously in copolyesters synthesized systematically from lactic acid, dimethyl terephthalate/terephthalic acid (TPA) and various diols [22, 23] or 2,5-furanodicarboxylic acid, ethylene glycol and L-lactic acid oligomer [28]. It is also interesting to note that the baseline deviation at $T_{\mathrm{g}}$, i.e. change in specific heat capacity $\left(\Delta C_{\mathrm{p}}\right)$ varies with the composition, increasing slightly along with the increase of PLA co-units content. An unusual increase of $\Delta C_{\mathrm{p}}$ up to $0.43 \mathrm{~J} /\left(\mathrm{g} \cdot{ }^{\circ} \mathrm{C}\right)$ has been observed for the PBT- $b$-PLA 30 copolymer, pointing to a large amount of the amorphous 


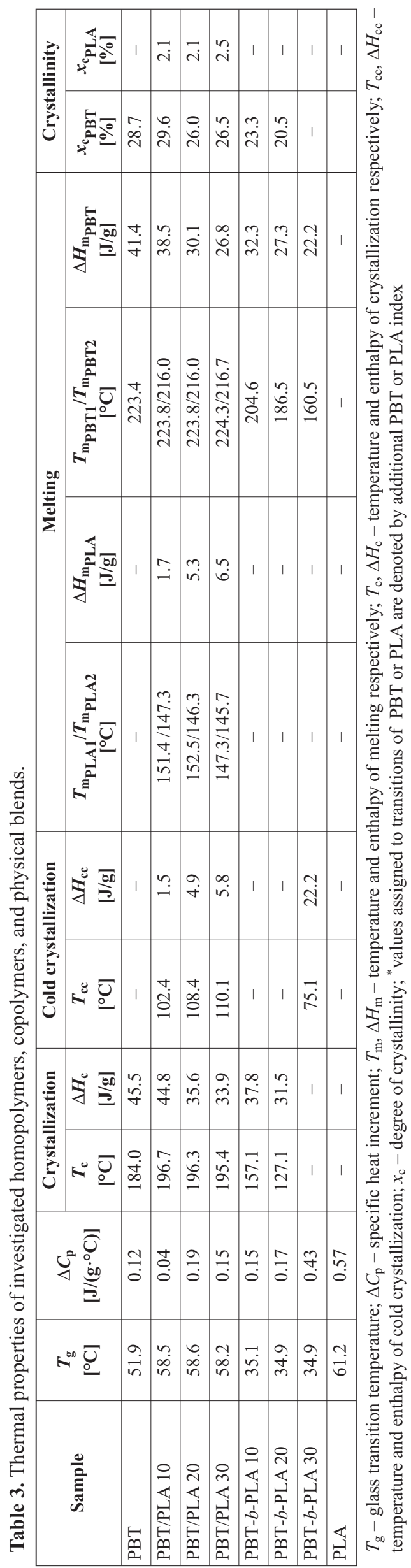

phase after cooling from the melt. Indeed, amorphous nature of this particular composition was discussed above on the basis of crystallization-melting behavior.

In order to verify the crystalline structure WAXS analysis was performed on the isothermally treated samples (annealed for $4 \mathrm{~h}$ at the temperature of about $15^{\circ} \mathrm{C}$ above $T_{\mathrm{c}}$ ). As derived from the diffraction profiles shown in Figure 7, all homopolymers, blends, and copolymers appeared as semi-crystalline materials after annealing.

All investigated PBT/PLA physical blends crystallize in the same structure as PBT homopolymer, as supported by the presence of characteristic diffraction peaks at scattering angles of ca. 16.6; 17.3; 20.6; 23.4 and $25.2^{\circ}$; assigned to the $(01 \overline{1}) ;(010)$; (111); (100) and (111) planes of $\alpha$-PBT form, respectively $[57,58]$. Moreover, in blends with the higher content of PLA ( $\geq 20 \mathrm{wt} \%$ ) additional crystalline phase develops, as revealed by characteristic reflection at $16.7^{\circ}(2 \theta)$ corresponding to the $(200 / 110)$ plane of PLA [52] (marked with red dotted line). The latter does not occur at PBT/PLA 10 diffraction profile,

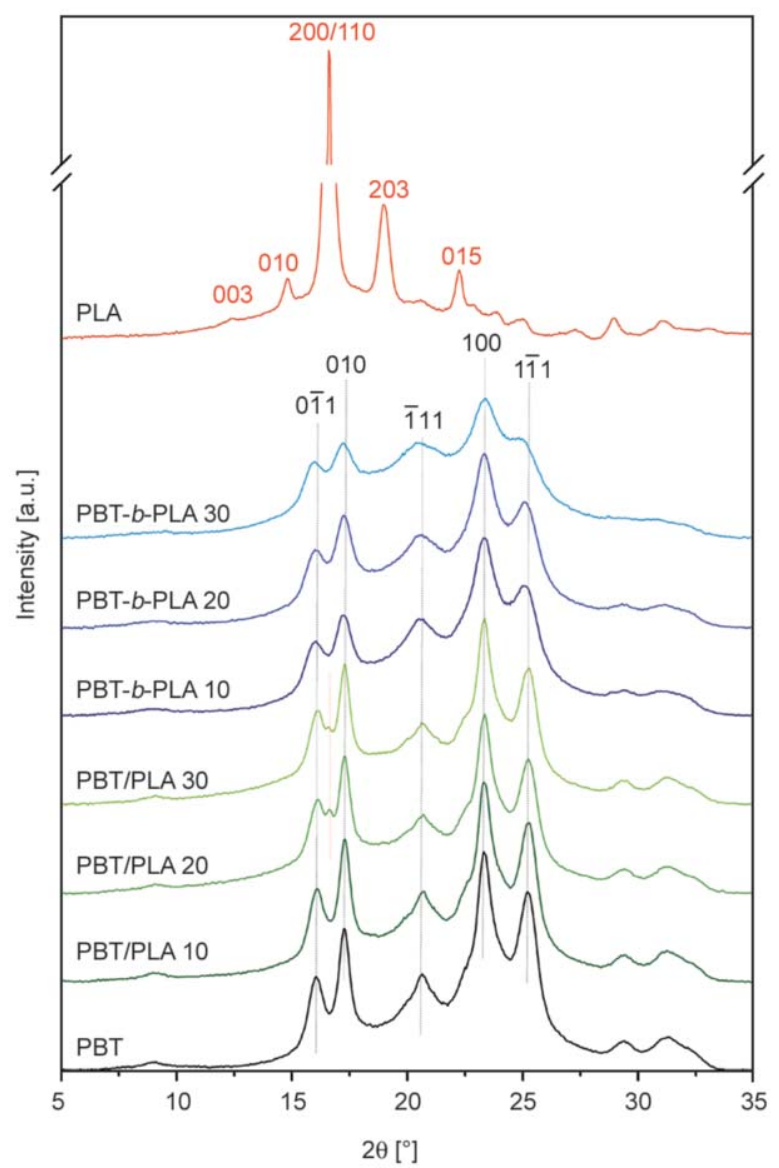

Figure 7. Wide-angle X-ray diffraction patterns recorded for PBT, PLA, copolymers, and blends. 
likely due to the extremely low amount of PLA crystalline phase, below $2 \mathrm{~J} / \mathrm{g}$ as measured from DSC heat of fusion (see Table 3). Anyway, sharp X-ray reflections with constant positions are evident, confirming that; (i) physical blends exhibit strong crystallization tendency and (ii) the crystal lattice parameters of individual components remain unchanged after physical blending, forming two independent crystalline structures.

When the diffractograms of PBT- $b$-PLA copolymers are concerned, Bragg maxima originating only from the crystal structure of $\alpha$-PBT occur. Moreover, as the amount of aliphatic $c o$-unit increases, the diffraction peaks become broader and less intense compared to that of PBT homopolymer and PBT/PLA blends, suggesting again that the structural ordering decreases in copolymer series. Nevertheless, at this point, it is worth emphasizing that PBT-b-PLA 30 sample tends to arrange into crystalline domains upon annealing, despite the fact that on fast cooling rates can be frozen in completely amorphous state (as evidenced in DSC experiments). The proceeding of the phase segregation to form crystalline phase is of particular importance when block copolymers are considered. As is well known, an increase in molecular weight and crystallization of constituent blocks favors microphase segregation $[33,47,55]$. No signs of PLA crystalline behavior has been detected neither at DSC melting curve nor at X-ray diffraction patterns of recorded for copolymers, confirming that rather short aliphatic LA sequences (i.e., $\mathrm{L}_{\mathrm{PLA}}<1.5$ ) have a minor impact on the molecular arrangement in the crystalline phase and are localized mainly in amorphous lamella. Previous reports on different copolymer systems showed that the minor component can be completely rejected from the crystalline phase, lowering the overall material crystallinity at the same time $[27,59,60]$. These findings explain well a decrease of crystallinity degree, observed with the increment of PLA co-unit in copolymers. Namely, with increasing PLA weight fraction, the amount of PBT crystallizable units diminishes, $\mathrm{L}_{T}$ sequences become gradually shorter and they are more distorted; consequently, chain packing becomes looser. The WAXS observations of both blends and copolymers superposed very well with sequence distribution analysis and calorimetric studies discussed above. The analysis of dynamic-mechanical behavior in the glass transition region can provide additional information about the morphology of investigated systems.
The temperature spectra of storage modulus recorded for all investigated systems are presented in Figure 8 . As can be seen, at low temperatures, the storage modulus $E^{\prime}$ of all materials remains roughly constant, exhibiting values characteristic for the glassy state. With further increase of temperature, the modulus decreases significantly due to the viscoelastic relaxation (glass-to-rubber transition). The wasted energy from viscous movement of polymer chains is reflected in the relaxation peak at $\tan \delta$ curve, called $\alpha$-relaxation, whose maximum can be considered as DMTA manifestation of $T_{\mathrm{g}}[61,62]$. As physical blends are considered, clear phase separation structure occurs, as revealed by two maxima on $\tan \delta$ curve (Figure $8 \mathrm{~b}$ ). Based on the homopolymers' $T_{\mathrm{g}}$ temperatures reported in Figure 8, one can ascribe the lower temperature relaxation $\left(\alpha_{1}\right)$ to the glass transition of amorphous PLA phase and the higher temperature peak $\left(\alpha_{2}\right)$ to the glass transition of PBT amorphous phase. In contrast, when reactive blending is carried on, the two maxima of $\alpha$ relaxation observed in physical blends are replaced by a single peak at $\tan \delta$ curve (Figure 8c), supporting the suggestion

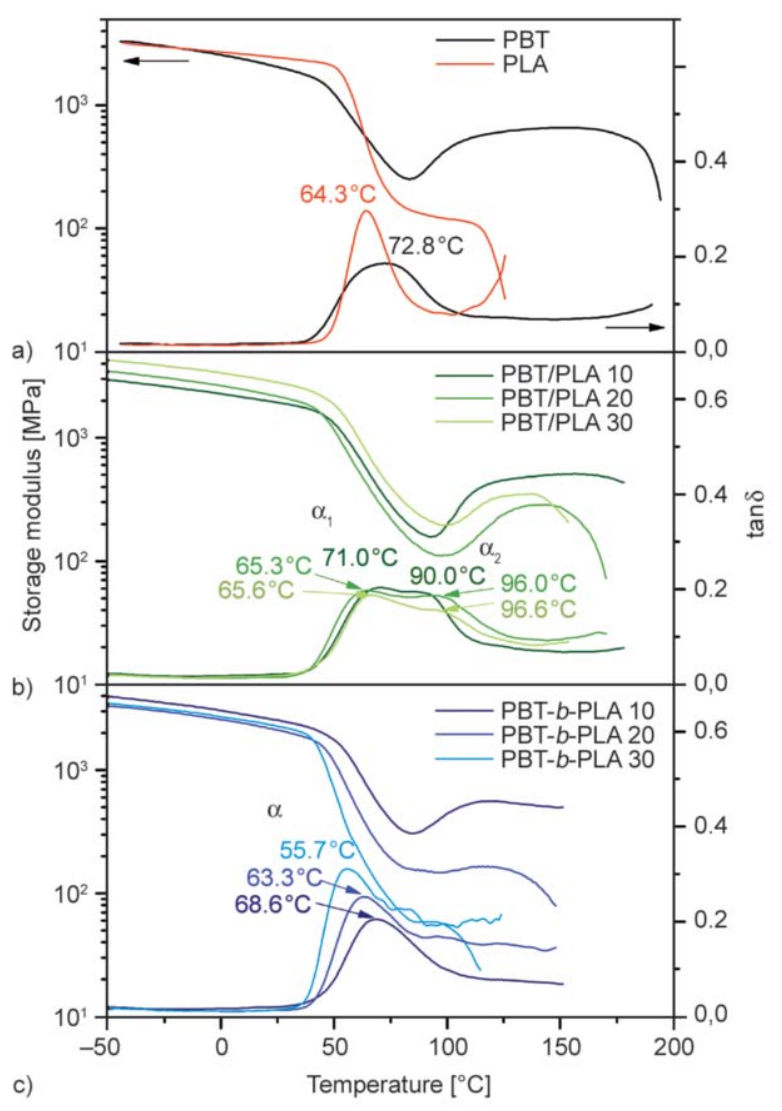

Figure 8. Temperature dependence of storage modulus and $\tan \delta$ for the investigated homopolymers (a), physical blends (b) and copolymers (c). 
that amorphous phase in reactive blended systems is homogenous, as already inferred from the calorimetric tests. Along with an increase of PLA co-unit content, the $T_{\mathrm{g}}$ peak position in $\tan \delta$ progressively shifts to lower temperature. Moreover, an increase in peak magnitude (from 0.2 to 0.3 for PBT- $b$-PLA 10 and PBT- $b$-PLA 30 samples, respectively) highlights once again that the chain stiffness decreases along with an increase of weight fraction of aliphatic LA units.

A drop, corresponding to the $T_{\mathrm{g}}$, is followed by an increase in storage modulus, resulting from cold crystallization phenomenon (marked prominently in PBT, blends and PBT- $b$-PLA 10 copolymer curves). This effect is not so evident in PLA and copolymers with higher amount of PLA (20 and $30 \mathrm{wt} \%$ ). Hu et al. [29] in their DMTA analysis on PBFLA copolymers, also observed that with increasing concentration of PLA, crystallization during heating is inhibited. They found that cold crystallization could not be identified if PBT sequence length is less than 4. In our DMTA experiment $\mathrm{PBT}$ sequence with length of $\sim 8$ (PBT$b$-PLA 20) crystallizes barely, while PBT characterized by $\mathrm{L}_{\mathrm{T}}$ of $\sim 5$ (PBT- $b$-PLA 30 ) does not crystallize at all. As the temperature increases, a second drop of $E^{\prime}$ modulus, associated with the polymer softening point $\left(T_{\mathrm{s}}\right)$ occurs. Irrespective of preparation method, $T_{\mathrm{g}}$ shifts to lower temperature value with an increase of PLA concentration. Moreover, this shift is much more pronounced in PBT- $b$-PLA systems, probably as a result of significant changes in the copolymers crystalline structure, as previously revealed by DSC and WAXS.

\subsection{Shape-memory behavior}

From the above-collected data one can note that PBT- $b$-PLA 30 copolymer is characterized by different and somehow peculiar behavior: (i) low glass transition temperature $\left(T_{\mathrm{g}}=34.9^{\circ} \mathrm{C}\right)$ accompanied by sudden gain in molecular mobility $\left(\Delta C_{\mathrm{p}}=\right.$ $\left.0.43 \mathrm{~J} /\left(\mathrm{g} \cdot{ }^{\circ} \mathrm{C}\right)\right)$, as derived from calorimetric data and (ii) abrupt decrease of $E^{\prime}$ during transition from glassy to rubbery state as observed from DMTA analysis (see bottom panel of Figure 8). From other studies $[53,63,64]$ it is known that the elastic ratio of glassy to rubbery modulus $\left(E_{\mathrm{g}}^{\prime} / E_{\mathrm{r}}^{\prime}\right)$ can be considered as a preliminary indicator of shape memory behavior. Generally, the grater this ratio is, the better the shape memory properties. In other words, shaping at $T>T_{\mathrm{g}}$ is easier and the resistance to deformation at
$T<T_{\mathrm{g}}$ is higher. Herein, $E_{\mathrm{g}}^{\prime}$ and $E_{\mathrm{r}}^{\prime}$ vary sufficiently, i.e. two orders of magnitude [65] to qualify PBT- $b$ PLA 30 copolymer to further studies on thermallyinduced shape-memory effect ( $E_{\mathrm{g}}^{\prime}$ of $3283 \mathrm{MPa}$ and $E_{\mathrm{r}}^{\prime}$ of $58 \mathrm{MPa}$ were measured). In order to estimate the extend of shape recovery quantitatively, more specific DMTA analysis was performed, by subjecting the sample to multiple thermomechanical cycles as shown in Figure 9. Firstly the sample was heated to $50^{\circ} \mathrm{C}$ (calorimetric $T_{\mathrm{g}}+15^{\circ} \mathrm{C}$ ), stretched by ramping a load of $\sim 10 \mathrm{~N}$, to approx. $9 \%$ and subsequently cooled down to a 'fixing' temperature of $0^{\circ} \mathrm{C}$, at constant load. After unloading the sample contracts a bit and retains a new temporary shape. Obtained results suggest that the investigated copolymer exhibits relatively high ability to fix mechanical deformation, with shape fixity efficiency $\left(R_{\mathrm{f}}\right)$ over $90 \%$ throughout 8 experimental cycles $\left(91.1 \leq R_{\mathrm{f}} \leq 92.0 \%\right)$. Upon reheating to $T_{\mathrm{g}}+15^{\circ} \mathrm{C}$ the sample recovers to the original shape, reaching shape recovery $\left(R_{\mathrm{r}}\right)$ of $94 \%$ in the first cycle. This characteristic improves further from one cycle to the next, giving the recovery efficiency above $99 \%$ in $N=8$. The $R_{\mathrm{r}}$ difference between first and successive cycles is consistent with previous observations on thermoplastic SMP $[38,66$, 67] and is related to the residual stain remaining after material processing.

The shape memory properties of PBT- $b$-PLA 30 sample are also demonstrated visually in Figure 10. The flower-shape sample of PBT- $b$-PLA 30 was heated with a hot gun to $\sim 50{ }^{\circ} \mathrm{C}$ and processed to a temporary shape. Then the folded shape was 'fixed' at ambient temperature and reheated to recover. At timelapse photos in bottom raw it can be seen that the flower appears to recover fully to the initial shape

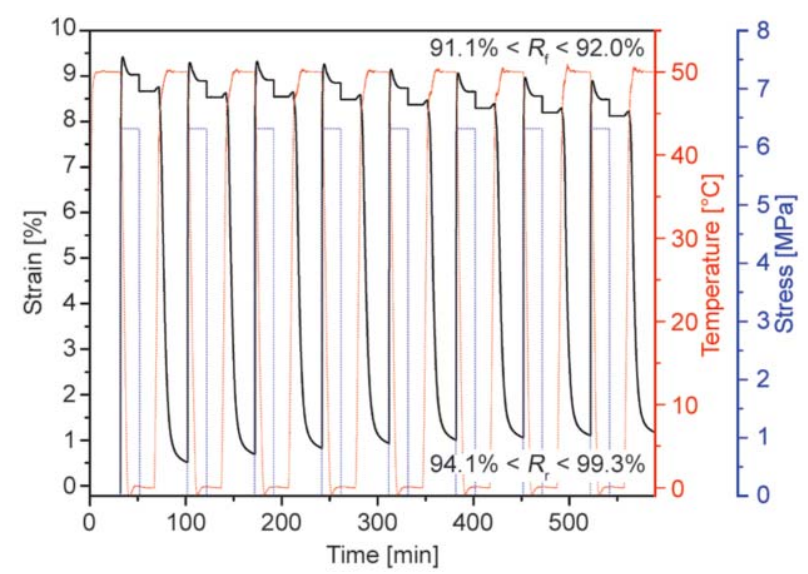

Figure 9. Shape memory cycles of PBT- $b$-PLA 30 copolymer (heating and cooling rate of $10^{\circ} \mathrm{C} / \mathrm{min}$ was employed). 


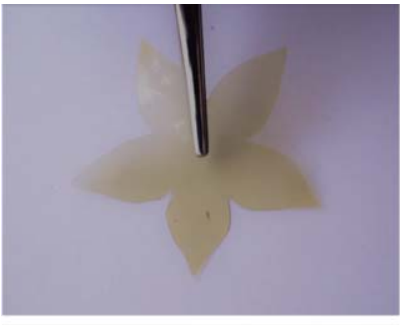

Initial shape
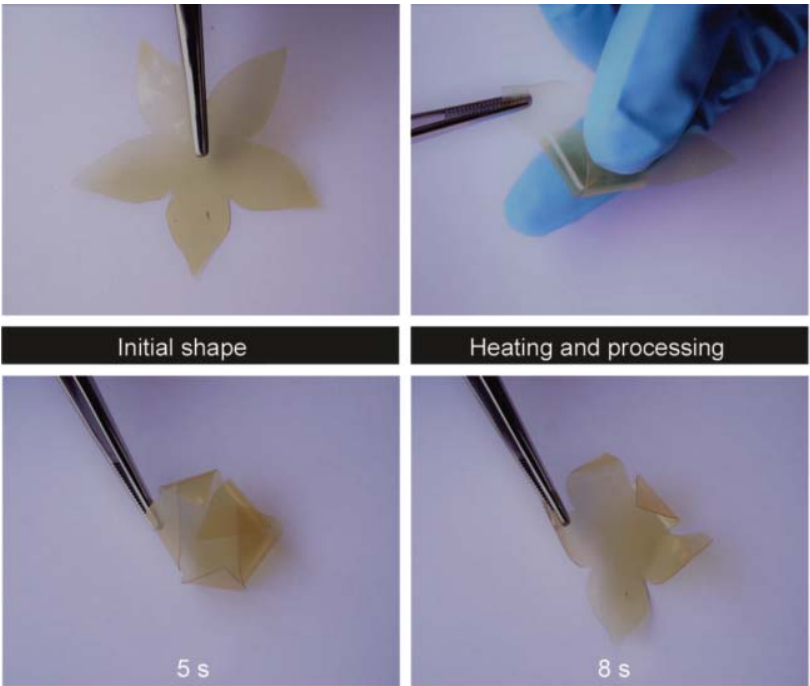

Heating and processing

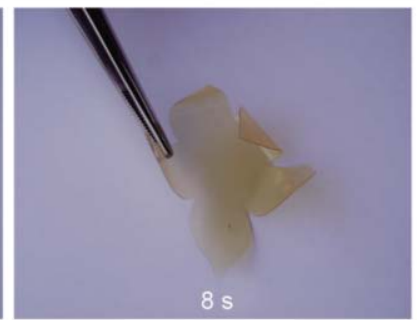

$8 \mathrm{~s}$

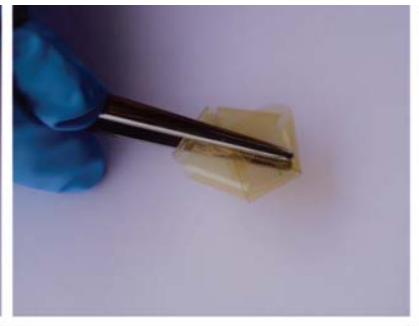

Cooling

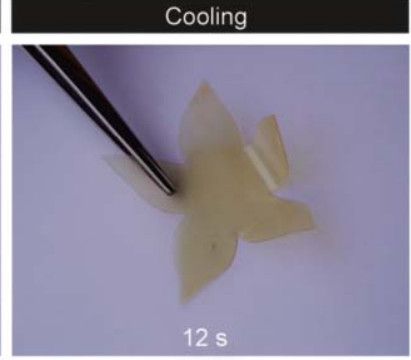

$12 s$

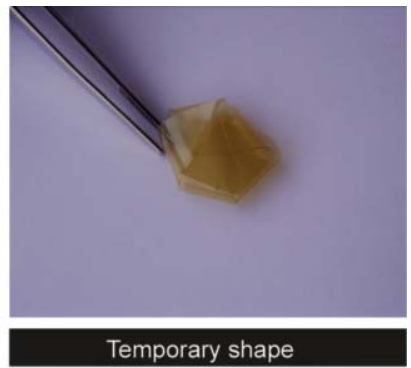

Temporary shape

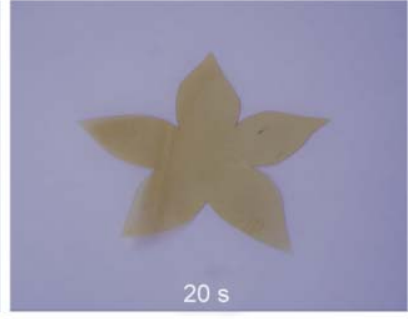

Recovered shape

Figure 10. Visual demonstration of shape memory behavior of PBT- $b$-PLA 30 copolymer.

within $20 \mathrm{~s}$. The process was repeated multiple times without any signs of sample damage.

\subsection{Thermal stability}

The thermal stability of specific materials is crucial to establish safe conditions during melt processing and to determine working temperature limit of final product. Therefore, the parent polymers, copolymers, and physical blends have been subjected to thermogravimetric analysis (TGA). The mass loss and derivative of mass loss curves in an air atmosphere are shown in Figure 11. The TGA traces of both homopolymers were found to exhibit two maxima of mass loss in an oxidizing atmosphere, the first major step attributed to the decomposition of polymer backbone (chain scission of the ester bonds) is followed by the minor step, attributed to an oxidative degradation process $[43,68]$. The PBT/PLA blends decomposition profile exhibit three distinct mass loss steps, two of them in the lower temperature range (300$435^{\circ} \mathrm{C}$ ). It is evident that the first mass loss step ranging from 300 to $369^{\circ} \mathrm{C}$ is related to PLA degradation, while the second step that appears at 370 $435^{\circ} \mathrm{C}$ can be attributed to the decomposition of PBT. Meanwhile, the degradation of individual blocks in PBT- $b$-PLA copolyesters merges into one step, exhibiting PBT-like profile. It is strongly suggested that short blocks copolymers investigated in present work behave in similar manner as random copolymers in terms of thermal stability. A similar tendency was reported earlier by $\mathrm{Hu}$ et al. [29] for PBF-PLA copolyesters.

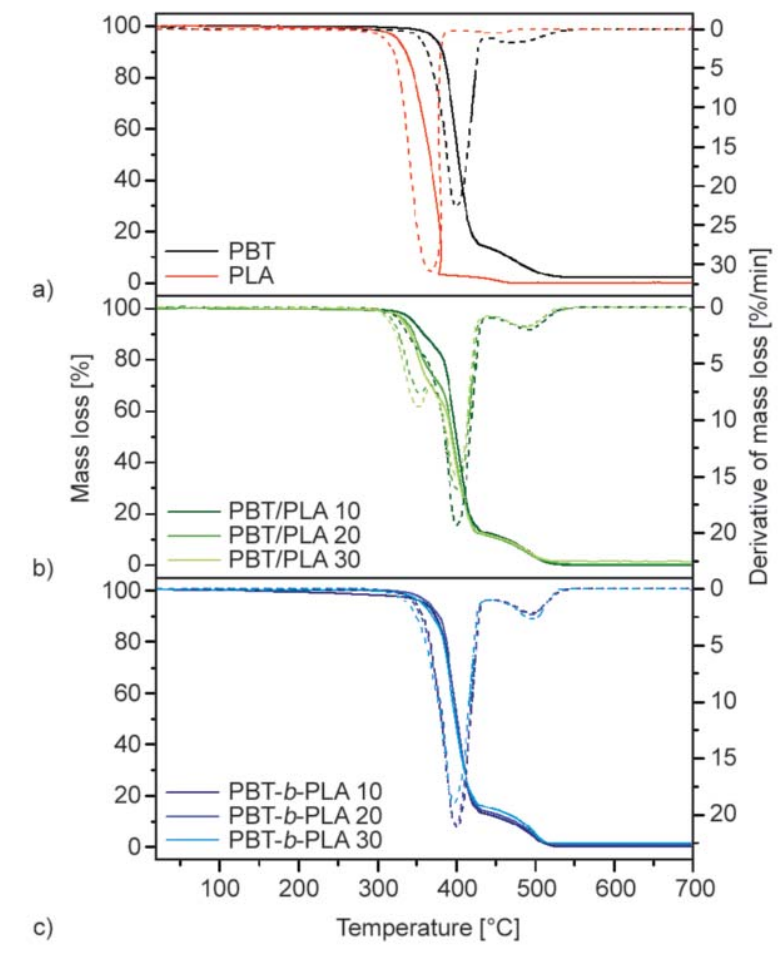

Figure 11. Mass loss and derivative of mass loss (dashed lines) as a function of temperature for homopolymers (a), physical blends (b) and copolymers (c).

The temperatures related to the initial decomposition at $5 \%$ loss of the original mass $\left(T_{\mathrm{d}, 5 \%}\right)$ and the temperatures corresponding to the maximum of mass loss rate $\left(\mathrm{T}_{\mathrm{DTG} 1}, T_{\mathrm{DTG} 2}\right.$, and $\left.T_{\mathrm{DTG} 3}\right)$ are collected in Table 4 . The onset degradation temperature corresponding to 5\% mass loss of both blends and copolymers shifts systematically to lower temperature with the increasing content of PLA segments, with the exception of PBT- $b$-PLA incorporating $20 \mathrm{wt} \%$ of PLA. 
Table 4. Characteristic temperatures of the thermo-oxidative decomposition of investigated homopolymers, copolymers, and physical blends.

\begin{tabular}{|l|c|c|c|c|}
\hline \multicolumn{1}{|c|}{ Sample } & $\begin{array}{c}\boldsymbol{T}_{\mathbf{d}, \mathbf{5} \%} \\
{\left[{ }^{\circ} \mathbf{C}\right]}\end{array}$ & $\begin{array}{c}\boldsymbol{T}_{\text {DTG1 }} \\
{\left[{ }^{\circ} \mathbf{C}\right]}\end{array}$ & $\begin{array}{c}\boldsymbol{T}_{\text {DTG2 }} \\
{\left[{ }^{\circ}{ }^{\circ} \mathbf{C}\right]}\end{array}$ & $\begin{array}{c}\boldsymbol{T}_{\text {DTG3 }} \\
{\left[{ }^{\circ} \mathbf{C}\right]}\end{array}$ \\
\hline PBT & 374 & - & 401 & 469 \\
\hline PBT/PLA 10 & 346 & - & 401 & 492 \\
\hline PBT/PLA 20 & 336 & 354 & 400 & 488 \\
\hline PBT/PLA 30 & 333 & 351 & 400 & 489 \\
\hline PBT-b-PLA 10 & 360 & - & 400 & 495 \\
\hline PBT- $b$-PLA 20 & 365 & - & 399 & 495 \\
\hline PBT- $b$-PLA 30 & 356 & - & 397 & 497 \\
\hline PLA & 325 & 368 & - & 449 \\
\hline
\end{tabular}

This behavior was already expected since PLA is more sensitive to thermal degradation than PBT. In particular, pure PLA exhibits $T_{\mathrm{d}, 5 \%}$ of $325^{\circ} \mathrm{C}$, which is $49^{\circ} \mathrm{C}$ lower than $T_{\mathrm{d}, 5 \%}$ recorded for PBT. However, it has to be emphasized that $T_{\mathrm{d}, 5 \%}$ occurs at notably higher temperatures in copolymers than in respective physical blends. An increase of $10^{\circ} \mathrm{C}$ was measured in the initial decomposition temperature of PBT- $b$-PLA 30 copolymer when compared to the PBT/PLA 10 blend, which are characterized by similar terephthalate to lactide units ratio. Apparently, less stable and relatively short LA aliphatic blocks are distributed along stable BG-T macromolecular chains; thus, their influence on thermal stability is much smaller than in respective physical blends. In regard to this hypothesis, slight decrease in $T_{\mathrm{d}, 5 \%}$ and $T_{\mathrm{DTG} 2}$ in PBT- $b$-PLA copolymers with an increasing fraction of LA moieties can be a consequence of aromatic sequences shortening and chain regularity disordering or the effect of LA degradation, or both. As to the decomposition of residue, it was found that the temperatures corresponding to the maximum of mass loss $\left(T_{\mathrm{DTG} 3}\right)$ of all copolymers and blends shifted toward higher values, with respect to PBT and PLA homopolyesters.

\subsection{Mechanical properties}

In an application perspective, the mechanical properties of the polymeric materials were evaluated. Figure 12 provides the representative stress-strain curves of the investigated polymers stored at room temperature for 4 weeks. The averaged values and standard deviations of Young's modulus $(E)$, stress at yield $\left(\sigma_{\mathrm{y}}\right)$, elongation at yield $\left(\varepsilon_{\mathrm{y}}\right)$, stress at break $\left(\sigma_{\mathrm{b}}\right)$ and elongation at break $\left(\varepsilon_{\mathrm{b}}\right)$ are listed in Table 5. By comparing the stress-strain curves of PBT and

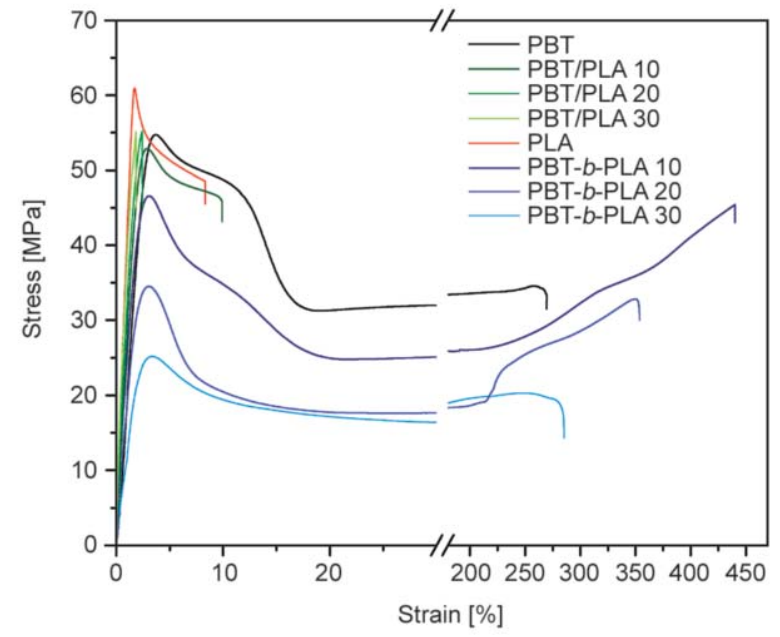

Figure 12. Representative stress-strain curves of PBT, PLA, copolymers and physical blends.

PLA homopolymers it is apparent that the former exhibit ductile behavior, whilst the latter is rather rigid and brittle in nature. It is also evident that the preparation process has a remarkable effect on the tensile properties of investigated PBT-PLA systems. However, at this point, one has to take into account that the variation of stress-strain behavior in two investigated series results mainly from differences in the morphology (see Figure 5) and crystallinity (Table 3). As specified in previous sections PBT/PLA physical blends are exhibiting typical morphological features of non-compatible systems and are highly crystalline, whereas reactive blends are characterized by improved compatibility and reduced amount of crystalline phase.

From collected results, it is obvious that tensile properties changed from ductile to brittle behavior by blending with PLA. Although the yield point can be distinguished at the stress-strain curve of PBT/PLA $90 / 10$, one can immediately see that the elongation at break decreased dramatically (by $\sim 96 \%$ compared to PBT homopolymer). This effect became more significant with further increase of PLA content, blends with 20 and $30 \mathrm{wt} \%$ broke abruptly after reaching the maximum stress of $\sim 55.8 \mathrm{MPa}$, at an elongation of $\sim 2.4$ and $\sim 1.8 \%$, respectively. That is to say, PBT/ PLA physical blends are even more brittle than PLA homopolymer. This behavior is common in immiscible non-compatibilized polymer blends $[17,69,70]$ as the interfacial adhesion is not sufficient and dispersed phase act as a nucleating agent, initiating and propagating the brittle fracture. Moreover, with increasing PLA weight fraction the stiffness (Young's 
Table 5. Tensile properties of investigated homopolymers, copolymers, and physical blends.

\begin{tabular}{|l|c|c|c|c|c|c|}
\hline \multicolumn{1}{|c|}{ Sample } & $\begin{array}{c}\boldsymbol{E} \\
{[\mathbf{G P a}]}\end{array}$ & $\begin{array}{c}\mathbf{\sigma}_{\mathbf{y}} \\
{[\mathbf{M P a}]}\end{array}$ & $\begin{array}{c}\boldsymbol{\varepsilon}_{\mathbf{y}} \\
{[\mathbf{\%}]}\end{array}$ & $\begin{array}{c}\boldsymbol{\sigma}_{\mathbf{b}} \\
{[\mathbf{M P a}]}\end{array}$ & $\begin{array}{c}\boldsymbol{\varepsilon}_{\mathbf{b}} \\
{[\mathbf{\%}]}\end{array}$ & $\begin{array}{c}\boldsymbol{H} \\
{\left[{ }^{\circ} \mathbf{S h} \mathbf{D}\right]}\end{array}$ \\
\hline PBT & $3.1 \pm 0.1$ & $53.3 \pm 0.6$ & $3.7 \pm 0.1$ & $33.6 \pm 1.6$ & $269.3 \pm 16.7$ & $71 \pm 1$ \\
\hline PBT/PLA 10 & $3.3 \pm 0.1$ & $52.9 \pm 0.8$ & $2.9 \pm 0.1$ & $45.8 \pm 0.6$ & $9.9 \pm 0.4$ & $76 \pm 1$ \\
\hline PBT/PLA 20 & $4.0 \pm 0.1$ & - & - & $55.2 \pm 0.8$ & $2.4 \pm 0.2$ & $79 \pm 1$ \\
\hline PBT/PLA 30 & $5.4 \pm 0.2$ & - & - & $55.2 \pm 0.7$ & $1.8 \pm 0.1$ & $80 \pm 1$ \\
\hline PBT-b-PLA 10 & $3.0 \pm 0.2$ & $46.6 \pm 1.0$ & $3.1 \pm 0.2$ & $45.7 \pm 1.2$ & $440.1 \pm 6.7$ & $75 \pm 1$ \\
\hline PBT-b-PLA 20 & $2.6 \pm 0.2$ & $34.5 \pm 0.3$ & $3.1 \pm 0.5$ & $32.7 \pm 0.6$ & $353.9 \pm 14.3$ & $72 \pm 1$ \\
\hline PBT-b-PLA 30 & $1.5 \pm 0.2$ & $25.2 \pm 2.2$ & $3.3 \pm 0.2$ & $19.8 \pm 0.7$ & $285.4 \pm 14.6$ & $68 \pm 1$ \\
\hline PLA & $5.4 \pm 0.1$ & $60.6 \pm 1.0$ & $1.7 \pm 0.1$ & $47.0 \pm 0.9$ & $8.3 \pm 0.2$ & $81 \pm 1$ \\
\hline
\end{tabular}

$E$ - Young's modulus; $\sigma_{\mathrm{y}}, \varepsilon_{\mathrm{y}}-$ tensile strength and elongation at yield, respectively; $\sigma_{\mathrm{b}}, \varepsilon_{\mathrm{b}}-$ tensile strength and elongation at break, respectively; $H$ - hardness

modulus) and hardness progressively increase, approaching the values characteristic of PLA homopolymer.

On the other hand, the PBT- $b$-PLA copolymers have a significantly different mechanical performance, which is characteristic for semi-crystalline polymers with a distinct yielding point, neck forming and finally strain hardening stage. It is clear that the applied method of reactive blending enhances interfacial adhesion between initially immiscible PBT-PLA polymer pair. All copolymers show an increase in $\varepsilon_{b}$ compared with homopolymers; maximum improvement of $440.1 \pm 6.7 \%$ is observed in PBT- $b$-PLA 10 copolyester, which is about $63 \%$ higher than elongation of PBT (269.3 $\pm 16.7 \%)$. Further increase in aliphatic units content slightly reduces $\varepsilon_{b}$. At copolymers stress-strain curves, strain hardening effect is evident as a result of macromolecular chains orientation and crystallization under tensile stress. However, one can note that this phenomenon is less pronounced in PBT$b$-PLA 30 copolymer, which exhibits poor crystallization ability. As expected, a decrease in the weight fraction and regularity of crystallizable PBT co-units (i.e., crystallinity degree) results in a decrease of tensile strength at both yield and break. The tensile strength at yield decreased from 46.6 to $25.2 \mathrm{MPa}$, whilst tensile strength at break decreased from 45.7 to $19.8 \mathrm{MPa}$ for PBT- $b$-PLA 10 and PBT- $b$-PLA 30, respectively. This is in agreement with the study of Hu et al. [29] dealing with comparable aliphatic-aromatic systems. The enhancement of ductility in copolymer series is also highlighted by the decrease in Young's modulus from 3.1 (PBT homopolymer) to $1.5 \mathrm{GPa}$ (PBT- $b$-PLA 30). Lastly, declined crystallinity leads to a decrease in polymer hardness from 75 to $68^{\circ} \mathrm{Sh} \mathrm{D}$ in copolymer series.

\section{Conclusions}

In this work, aromatic-aliphatic PBT- $b$-PLA copolymers were prepared by reactive melt blending, i.e. introduction of PLA in the PBT polycondensate followed by conventional polycondensation reaction. A set of ${ }^{1} \mathrm{H}$ NMR and ATR-FTIR investigations confirmed unambiguously that the lactide moieties were successfully incorporated into PBT backbone. Furthermore, the applied method promotes the organization of terephthalate, butylene and lactide repeating units in blocks of different lengths, as detected by ${ }^{1} \mathrm{H}$ NMR sequence analysis. The number average weight $\left(\overline{M_{\mathrm{n}}}\right)$ of synthesized copolyesters range from 32156 to $26488 \mathrm{~g} / \mathrm{mol}$. Obtained copolymers were further compared to PBT and PLA homopolymers and PBT/PLA physical blends prepared simply by extrusion process.

By applying different methods of preparation, i.e. physical and reactive blending, two systems with significantly differing properties were obtained. The PBT and PLA are immiscible in the molten state and appeared as phase separated systems when prepared by extrusion. It was found that physical blending with PLA accelerated PBT crystallization when cooling from the melt and promoted the cold crystallization of PLA. As expected, high crystallinity degree and poor miscibility in PBT/PLA physical blends resulted in brittle fracture behavior. Although the calculations based on theoretical group contribution methods suggested immiscibility of PBT and PLA, one can draw a conclusion that in reactive blends compatibility increased as a result of chemical bonding between the functional groups of PBT and PLA (ester linkages). On the basis of two different experimental approaches (DSC and DMTA studies), it was affirmed that only one amorphous phase was formed in copolymer 
systems. Nevertheless, the micro-phase separation was found to develop owing to the presence of crystallizing PBT blocks. The thermal and structural properties strongly depend on the aromatic block length. It has been observed, that the crystallinity degree and melting temperature decreased along with decreasing PBT block length (increment of PLA content) in copolymer. That is to say one can control the crystallinity in copolymers by controlling the PBT to PLA ratio. Copolymerization with PLA significantly affected the mechanical performance, providing high elongation but at the same time reducing Young's modulus, yield strength, and strength at break. Incorporation of PLA leads to a drop in the thermal stability of both copolymers and blends with respect to PBT. However, it should be emphasized that this effect was less pronounced in copolymers than in physical blends. All copolymers remained stable up to temperature as high as $356^{\circ} \mathrm{C}$.

Additionally, the PBT- $b$-PLA 30 copolymer developed herein exhibits a range of attractive features including low glass transition temperature of $\sim 35^{\circ} \mathrm{C}$, amorphous structure (with the ability to develop morphology by isothermal crystallization), ability to elongate substantially as much as $\sim 285 \%$ and finally shape memory properties. It has been found that the mechanism of its shape memory behavior benefits from glass transition temperature. The PBT- $b$-PLA 30 copolymer showed satisfactory shape-fixity $(\geq 91 \%)$ and shape recovery efficiency $(\geq 94 \%)$ that remained reproducible over multiple shape memory cycles. It is believed that these properties make PBT- $b$-PLA copolymer an interesting candidate for a wide range of applications.

\section{Acknowledgements}

This work was financially supported by the West Pomeranian University of Technology, Start-Up Deans Grant for Young Scientists.

\section{References}

[1] Scheirs J., Long T. E.: Modern polyesters: Chemistry and technology of polyesters and copolyesters. Wiley, Chichester (2003).

[2] Peters E. N.: Engineering thermoplastics - Materials, properties, trends. in 'Applied plastics engineering handbook' (ed.: Kutz M.) William Andrew Publishing, Oxford, 3-26 (2016).

https://doi.org/10.1016/B978-0-323-39040-8.00001-8
[3] Genovese L., Lotti N., Gazzano M., Siracusa V., Dalla Rosa M., Munari A.: Novel biodegradable aliphatic copolyesters based on poly(butylene succinate) containing thioether-linkages for sustainable food packaging applications. Polymer Degradation and Stability, 132, 191-201 (2016).

https://doi.org/10.1016/J.polymdegradstab.2016.02.022

[4] Auras R., Harte B., Selke S.: An overview of polylactides as packaging materials. Macromolecular Bioscience, 4, 835-864 (2004).

https://doi.org/10.1002/mabi.200400043

[5] Wang L., Wang Y., Zhang F., Bai Y., Ding L.: Syntheses and properties of the PET-co-PEA copolyester. Journal of Applied Polymer Science, 134, 44967/1-44967/9 (2017).

https://doi.org/10.1002/app.44967

[6] Li W-D., Zeng J-B., Lou X-J., Zhang J-J., Wang Y-Z.: Aromatic-aliphatic random and block copolyesters: Synthesis, sequence distribution and thermal properties. Polymer Chemistry, 3, 1344-1353 (2012).

https://doi.org/10.1039/c2py20068f

[7] Siegenthaler K. O., Künkel A., Skupin G., Yamamoto M.: Ecoflex ${ }^{\circledR}$ and Ecovio ${ }^{\circledR}$ : Biodegradable, performance-enabling plastics. in 'Synthetic biodegradable polymers' (eds.: Rieger B., Künkel A., Coates G. W., Reichardt R., Dinjus E., Zevaco T. A.) Springer, Berlin, Heidelberg, 91-136 (2011).

https://doi.org/10.1007/12 2010106

[8] Müller R-J., Kleeberg I., Deckwer W-D.: Biodegradation of polyesters containing aromatic constituents. Journal of Biotechnology, 86, 87-95 (2001). https://doi.org/10.1016/S0168-1656(00)00407-7

[9] Garlotta D.: A literature review of poly(lactic acid). Journal of Polymers and the Environment, 9, 63-84 (2001). https://doi.org/10.1023/A:1020200822435

[10] Farah S., Anderson D. G., Langer R.: Physical and mechanical properties of PLA, and their functions in widespread applications - A comprehensive review. Advanced Drug Delivery Reviews, 107, 367-392 (2016). https://doi.org/10.1016/j.addr.2016.06.012

[11] Miyata T., Masuko T.: Crystallization behaviour of poly(L-lactide). Polymer, 39, 5515-5521 (1998). https://doi.org/10.1016/S0032-3861(97)10203-8

[12] Yasuniwa M., Tsubakihara S., Ohoshita K., Tokudome S.: X-ray studies on the double melting behavior of poly(butylene terephthalate). Journal of Polymer Science Part B: Polymer Physics, 39, 2005-2015 (2001). https://doi.org/10.1002/polb.1176

[13] Auras R., Lim L-T., Selke S., Tsuji H.: Poly(lactic acid): Synthesis, structures, properties, processing, and applications. Wiley, Hoboken (2010).

[14] Di Lorenzo M. L., Rubino P., Cocca M.: Isothermal and non-isothermal crystallization of poly(L-lactic acid)/ poly(butylene terephthalate) blends. Journal of Applied Polymer Science, 131, 40372/1-40372/8 (2014). https://doi.org/10.1002/app.40372 
[15] Di Lorenzo M. L., Rubino P., Cocca M.: Miscibility and properties of poly(L-lactic acid)/poly(butylene terephthalate) blends. European Polymer Journal, 49, 3309 3317 (2013).

https://doi.org/10.1016/J.eurpolymj.2013.06.038

[16] Samthong C., Deetuam C., Yamaguchi M., Praserthdam P., Somwangthanaroj A.: Effects of size and shape of dispersed poly(butylene terephthalate) on isothermal crystallization kinetics and morphology of poly(lactic acid) blends. Polymer Engineering and Science, 56, 258-268 (2016).

https://doi.org/10.1002/pen.24246

[17] Santos L. G., Costa L. C., Pessan L. A.: Development of biodegradable PLA/PBT nanoblends. Journal of Applied Polymer Science, 135, 45951/1-45951/9 (2018). https://doi.org/10.1002/app.45951

[18] Pivsa-Art W., Chaiyasat A., Pivsa-Art S., Yamane H., Ohara H.: Preparation of polymer blends between poly (lactic acid) and poly(butylene adipate-co-terephthalate) and biodegradable polymers as compatibilizers. Energy Procedia, 34, 549-554 (2013).

https://doi.org/10.1016/J.egypro.2013.06.784

[19] Cardoso E. C. L., Oliveira R. R., Machado G. A. F., Moura E. A. B.: Study of flexible films prepared from PLA/PBAT blend and PLA E-beam irradiated as compatibilizing agent. in 'Characterization of minerals, metals, and materials 2017' (eds.: Ikhmayies S., Li B., Carpenter J. S., Li J., Hwang J-Y., Monteiro S. N., Firrao D., Zhang M., Peng Z., Escobedo-Diaz J. P., Bai C., Kalay Y. E., Goswami R., Kim J.) Springer, Cham, 121-130 (2017).

[20] Al-Itry R., Lamnawar K., Maazouz A.: Improvement of thermal stability, rheological and mechanical properties of PLA, PBAT and their blends by reactive extrusion with functionalized epoxy. Polymer Degradation and Stability, 97, 1898-1914 (2012).

https://doi.org/10.1016/J.polymdegradstab.2012.06.028

[21] Opaprakasit M., Petchsuk A., Opaprakasit P., Chongprakobkit S.: Effects of synthesis conditions on chemical structures and physical properties of copolyesters from lactic acid, ethylene glycol and dimethyl terephthalate. Express Polymer Letters, 3, 458-468 (2009). https://doi.org/10.3144/expresspolymlett.2009.56

[22] Sriromreun P., Opaprakasit M., Petchsuk A., Opaprakasit P.: Synthesis and characterization of degradable poly (ethylene terephthalate-co-lactic acid) and its blends. Advanced Materials Research, 55-57, 789-792 (2009). https://doi.org/10.4028/www.scientific.net/amr.55-57.789

[23] Namkajorn M., Petchsuk A., Opaprakasit M., Opaprakasit P.: Synthesis and characterizations of degradable aliphatic-aromatic copolyesters from lactic acid, dimethyl terephthalate and diol: Effects of diol type and monomer feed ratio. Express Polymer Letters, 4, 415422 (2010).

https://doi.org/10.3144/expresspolymlett.2010.52
[24] Olewnik E., Czerwiński W., Nowaczyk J., Sepulchre M-O., Tessier M., Salhi S., Fradet A.: Synthesis and structural study of copolymers of L-lactic acid and bis (2-hydroxyethyl terephthalate). European Polymer Journal, 43, 1009-1019 (2007).

https://doi.org/10.1016/J.eurpolymj.2006.11.025

[25] Olewnik E., Czerwiński W., Nowaczyk J.: Hydrolytic degradation of copolymers based on L-lactic acid and bis-2-hydroxyethyl terephthalate. Polymer Degradation and Stability, 92, 24-31 (2007).

https://doi.org/10.1016/j.polymdegradstab.2006.10.003

[26] Wang B-T., Zhang Y., Song P-A., Guo Z-H., Cheng J., Fang Z-P.: Biodegradable aliphatic/aromatic copolyesters based on terephthalic acid and poly(L-lactic acid): Synthesis, characterization and hydrolytic degradation. Chinese Journal of Polymer Science, 28, 405415 (2010). https://doi.org/10.1007/s10118-010-9032-y

[27] Li J., Jiang Z-Q., Wang Z-B., Chen P., Li Y., Zhou J., Liu J., Wang Y-Z., Gu Q.: Synthesis, crystallization and hydrolysis of aromatic-aliphatic copolyester: Poly(trimethylene terephthalate)-co-poly(L-lactic acid). Polymer Degradation and Stability, 96, 991-999 (2011). https://doi.org/10.1016/J.polymdegradstab.2011.01.023

[28] Matos M., Sousa A. F., Fonseca A. C., Freire C. S. R., Coelho J. F. J., Silvestre A. J. D.: A new generation of furanic copolyesters with enhanced degradability: Poly (ethylene 2,5-furandicarboxylate)-co-poly(lactic acid) copolyesters. Macromolecular Chemistry and Physics, 215, 2175-2184 (2014).

https://doi.org/10.1002/macp.201400175

[29] Hu H., Zhang R., Shi L., Ying W. B., Wang J., Zhu J.: Modification of poly(butylene 2,5-furandicarboxylate) with lactic acid for biodegradable copolyesters with good mechanical and barrier properties. Industrial and Engineering Chemistry Research, 57, 11020-11030 (2018).

https://doi.org/10.1021/acs.iecr.8b02169

[30] Zhou J., Jiang Z., Wang Z., Zhang J., Li J., Li Y., Zhang J., Chen P., Gu Q.: Synthesis and characterization of triblock copolymer PLA- $b$-PBT- $b$-PLA and its effect on the crystallization of PLA. RSC Advances, 3, 18464 18473 (2013).

https://doi.org/10.1039/c3ra42096e

[31] Park S. S., Chae S. H., Im S. S.: Transesterification and crystallization behavior of poly(butylene succinate)/ poly(butylene terephthalate) block copolymers. Journal of Polymer Science Part A: Polymer Chemistry, 36, 147-156 (1998).

https://doi.org/10.1002/(SICI)10990518(19980115)36:1<147::AID-POLA19>3.0.CO;2-J

[32] Kint D. P. R., Alla A., Deloret E., Campos J. L., MuñozGuerra S.: Synthesis, characterization, and properties of poly(ethylene terephthalate)/poly(1,4-butylene succinate) block copolymers. Polymer, 44, 1321-1330 (2003). https://doi.org/10.1016/S0032-3861(02)00938-2 
[33] Soccio M., Lotti N., Finelli L., Gazzano M., Munari A.: Influence of transesterification reactions on the miscibility and thermal properties of poly(butylene/diethylene succinate) copolymers. European Polymer Journal, 44, 1722-1732 (2008).

https://doi.org/10.1016/J.eurpolymj.2008.03.022

[34] Muralisrinivasan N. S.: Polymer blends and composites: Chemistry and technology. Scrivener, Beverly (2017).

[35] Di Lorenzo M. L., Rubino P., Cocca M.: Miscibility and properties of poly(L-lactic acid)/poly(butylene terephthalate) blends. European Polymer Journal, 49, 33093317 (2013).

https://doi.org/10.1016/j.eurpolymj.2013.06.038

[36] Piesowicz E., Irska I., Bratychak M., Rosłaniec Z.: Poly(butylene terephthalate)/carbon nanotubes nanocomposites. Part I. Carbon nanotubes functionalization and in situ synthesis. Polimery, 60, 680-685 (2015). https://doi.org/10.14314/polimery.2015.680

[37] Deschamps A. A., Grijpma D. W., Feijen J.: Poly(ethylene oxide)/poly(butylene terephthalate) segmented block copolymers: The effect of copolymer composition on physical properties and degradation behavior. Polymer, 42, 9335-9345 (2001).

https://doi.org/10.1016/S0032-3861(01)00453-0

[38] Xie F., Huang C., Wang F., Huang L., Weiss R. A., Leng J., Liu Y.: Carboxyl-terminated polybutadiene-poly (styrene-co-4-vinylpyridine) supramolecular thermoplastic elastomers and their shape memory behavior. Macromolecules, 49, 7322-7330 (2016).

https://doi.org/10.1021/acs.macromol.6b01785

[39] Kodjie S. L., Li L., Li B., Cai W., Li C. Y., Keating M.: Morphology and crystallization behavior of HDPE/ CNT nanocomposite. Journal of Macromolecular Science Part B, Physics, 45, 231-245 (2006).

https://doi.org/10.1080/00222340500522299

[40] Chrissafis K., Paraskevopoulos K. M., Bikiaris D. N.: Thermal degradation kinetics of the biodegradable aliphatic polyester, poly(propylene succinate). Polymer Degradation and Stability, 91, 60-68 (2006). https://doi.org/10.1016/j.polymdegradstab.2005.04.028

[41] Chieng B., Ibrahim N., Yunus W., Hussein M.: Poly (lactic acid)/poly(ethylene glycol) polymer nanocomposites: Effects of graphene nanoplatelets. Polymers, 6, 93-104 (2013).

https://doi.org/10.3390/polym6010093

[42] Yamadera R., Murano M.: The determination of randomness in copolyesters by high resolution nuclear magnetic resonance. Journal of Polymer Science Part A-1: Polymer Chemistry, 5, 2259-2268 (1967). https://doi.org/10.1002/pol.1967.150050905

[43] Wojtczak M., Dutkiewicz S., Galeski A., Gutowska A.: Classification of aliphatic-butylene terephthalate copolyesters in relation to aliphatic/aromatic ratio. Polymer, 113, 119-134 (2017).

https://doi.org/10.1016/J.polymer.2017.02.054
[44] Gigli M., Govoni M., Lotti N., Giordano E. D., Gazzano M., Munari A.: Biocompatible multiblock aliphatic polyesters containing ether-linkages: Influence of molecular architecture on solid-state properties and hydrolysis rate. RSC Advances, 4, 32965-32976 (2014). https://doi.org/10.1039/C4RA04248D

[45] Witt U., Einig T., Yamamoto M., Kleeberg I., Deckwer W-D., Müller R-J.: Biodegradation of aliphatic-aromatic copolyesters: Evaluation of the final biodegradability and ecotoxicological impact of degradation intermediates. Chemosphere, 44, 289-299 (2001).

https://doi.org/10.1016/S0045-6535(00)00162-4

[46] Steinborn-Rogulska I., Rokicki G.: Solid-state polycondensation (SSP) as a method to obtain high molecular weight polymers. Part I. Parameters influencing the SSP process. Polimery, 58, 3-13 (2013).

https://doi.org/10.14314/polimery.2013.003

[47] Kwiatkowska M., Kowalczyk I., Kwiatkowski K., Szymczyk A., Rosłaniec Z.: Fully biobased multiblock copolymers of furan-aromatic polyester and dimerized fatty acid: Synthesis and characterization. Polymer, 99, 503-512 (2016).

https://doi.org/10.1016/j.polymer.2016.07.060

[48] Taraghi I., Fereidoon A., Paszkiewicz S., Szymczyk A., Chylinska R., Kochmanska A., Roslaniec Z.: Microstructure, thermal stability, and mechanical properties of modified polycarbonate with polyolefin and silica nanoparticles. Polymers for Advanced Technologies, 28, 1794-1803 (2017). https://doi.org/10.1002/pat.4064

[49] Paszkiewicz S., Irska I., Piesowicz E., Pilawka R., Pawelec I., Szymczyk A., Gorący K., Wielgosz Z., Rosłaniec Z.: Synthesis and characterization of new poly(ethylene terephthalate)/poly(phenylene oxide) blends. Polimery, 62, 93-100 (2017).

https://doi.org/10.14314/polimery.2017.093

[50] Krevelen D. W., Nijenhuis K.: Properties of polymers: Their correlation with chemical structure; their numerical estimation and prediction from additive group contributions. Elsevier, Amsterdam (2009).

[51] Pillin I., Montrelay N., Grohens Y.: Thermo-mechanical characterization of plasticized PLA: Is the miscibility the only significant factor? Polymer, 47, 4676-4682 (2006). https://doi.org/10.1016/j.polymer.2006.04.013

[52] Zhang J., Tashiro K., Tsuji H., Domb A. J.: Disorderto-order phase transition and multiple melting behavior of poly(L-lactide) investigated by simultaneous measurements of WAXD and DSC. Macromolecules, 41, 1352-1357 (2008). https://doi.org/10.1021/MA0706071

[53] Fakirov S.: Handbook of condensation thermoplastic elastomer. Wiley, Weinheim (2005). 
[54] Ou C-F., Chao M-S., Huang S-L.: The crystallization behaviors of poly(butylene terephthalate) blended with $c o[$ poly(butylene terephthalate- $p$-oxybenzoate)] copolyesters. European Polymer Journal, 36, 2665-2670 (2000).

https://doi.org/10.1016/S0014-3057(00)00047-1

[55] Deschamps A. A., Grijpma D. W., Feijen J.: Poly(ethylene oxide)/poly(butylene terephthalate) segmented block copolymers: The effect of copolymer composition on physical properties and degradation behavior. Polymer, 42, 9335-9345 (2001).

https://doi.org/10.1016/S0032-3861(01)00453-0

[56] Guidotti G., Soccio M., Siracusa V., Gazzano M., Salatelli E., Munari A., Lotti N.: Novel random PBS-based copolymers containing aliphatic side chains for sustainable flexible food packaging. Polymers, 9, 724/1-724/16 (2017). https://doi.org/10.3390/polym9120724

[57] Yokouchi M., Sakakibara Y., Chatani Y., Tadokoro H., Tanaka T., Yoda K.: Structures of two crystalline forms of poly(butylene terephthalate) and reversible transition between them by mechanical deformation. Macromolecules, 9, 266-273 (1976).

https://doi.org/10.1021/ma60050a018

[58] Bornschlegl E., Bonart R.: Small angle X-ray scattering studies of poly(ethylene terephthalate) and poly(butylene terephthalate). Colloid and Polymer Science, 258, 319-331 (1980).

https://doi.org/10.1007/BF01466670

[59] Shinotsuka K., Assender H. E., Claridge T. D. W.: Synthesis of statistical PET/PEN random block copolymers and their crystallizability in the bulk and at the surface. Journal of Applied Polymer Science, 135, 46515/146515/11 (2018).

https://doi.org/10.1002/app.46515

[60] Papadopoulos L., Magaziotis A., Nerantzaki M., Terzopoulou Z., Papageorgiou G. Z., Bikiaris D. N.: Synthesis and characterization of novel poly(ethylene furanoate-co-adipate) random copolyesters with enhanced biodegradability. Polymer Degradation and Stability, 156, 32-42 (2018).

https://doi.org/10.1016/J.polymdegradstab.2018.08.002

[61] Szymczyk A., Senderek E., Nastalczyk J., Roslaniec Z.: New multiblock poly(ether-ester)s based on poly(trimethylene terephthalate) as rigid segments. European Polymer Journal, 44, 436-443 (2008).

https://doi.org/10.1016/J.eurpolymj.2007.11.005
[62] Kwiatkowska M., Kowalczyk I., Kwiatkowski K., Szymczyk A., Jędrzejewski R.: Synthesis and structure - property relationship of biobased poly(butylene 2,5furanoate $)$ - block - (dimerized fatty acid) copolymers. Polymer, 130, 26-38 (2017).

https://doi.org/10.1016/J.polymer.2017.10.009

[63] Kim B. K., Lee S. Y., Lee J. S., Baek S. H., Choi Y. J., Lee J. O., Xu M.: Polyurethane ionomers having shape memory effects. Polymer, 39, 2803-2808 (1998). https://doi.org/10.1016/S0032-3861(97)00616-2

[64] Liu G., Xie D., Li Y., Zhang Y., Huang F.: Shape memory properties of poly(methyl methacrylate-co-2-hydroxyethyl methacrylate)/poly(ethylene glycol) complexes. Polimery, 58, 304-307 (2013). https://doi.org/10.14314/polimery.2013.304

[65] Cao Y., Guan Y., Du J., Luo J., Peng Y., Yip C. W., Chan A. S. C.: Hydrogen-bonded polymer network - Poly (ethylene glycol) complexes with shape memory effect. Journal of Materials Chemistry, 12, 2957-2960 (2002). https://doi.org/10.1039/b207024n

[66] Shi Y., Weiss R. A.: Sulfonated poly(ether ether ketone) ionomers and their high temperature shape memory behavior. Macromolecules, 47, 1732-1740 (2014). https://doi.org/10.1021/ma500119k

[67] Xiao X., Kong D., Qiu X., Zhang W., Liu Y., Zhang S., Zhang F., Hu Y., Leng J.: Shape memory polymers with high and low temperature resistant properties. Scientific Reports, 5, 14137/1-14137/12 (2015). https://doi.org/10.1038/srep14137

[68] Li F., Xu X., Li Q., Li Y., Zhang H., Yu J., Cao A.: Thermal degradation and their kinetics of biodegradable poly(butylene succinate-co-butylene terephthate)s under nitrogen and air atmospheres. Polymer Degradation and Stability, 91, 1685-1693 (2006).

https://doi.org/10.1016/J.polymdegradstab.2005.12.005

[69] Djellali S., Haddaoui N., Sadoun T., Bergeret A., Grohens Y.: Structural, morphological and mechanical characteristics of polyethylene, poly(lactic acid) and poly (ethylene-co-glycidyl methacrylate) blends. Iranian Polymer Journal, 22, 245-257 (2013).

https://doi.org/10.1007/s13726-013-0126-6

[70] Moghaddam M. R. A., Razavi S. M. A., Jahani Y.: Effects of compatibilizer and thermoplastic starch (TPS) concentration on morphological, rheological, tensile, thermal and moisture sorption properties of plasticized polylactic acid/TPS blends. Journal of Polymers and the Environment, 26, 3202-3215 (2018).

https://doi.org/10.1007/s10924-018-1206-7 